\title{
Booms, Recessions and Financial Turmoil: A Fresh Look at Investment Decisions under Cyclical Uncertainty
}

\author{
Yu-Fu Chen \\ Michael Funke
}

\author{
CESIFO WORKING PAPER NO. 2759 \\ CATEgory 6: FisCAl Policy, MACROECONOMICS AND GROWTH \\ August 2009
}

Presented At CESifo Venice Summer Institute, July 2009
An electronic version of the paper may be downloaded
- from the SSRN website:
- from the RePEc website:
www.SSRN.com
from the CESifo website:
www.RePEc.org
www.CESifo-group.org/wp 


\title{
Booms, Recessions and Financial Turmoil: A Fresh Look at Investment Decisions under Cyclical Uncertainty
}

\begin{abstract}
The paper studies the interaction between cyclical uncertainty and investment in a stochastic real option framework where demand shifts stochastically between three different states, each with different rates of drift and volatility. In our setting the shifts are governed by a three-state Markov switching model with constant transition probabilities. The magnitude of the link between cyclical uncertainty and investment is quantified using simulations of the model. The chief implication of the model is that recessions and financial turmoil are important catalysts for waiting. In other words, our model shows that macroeconomic risk acts as an important deterrent to investments.
\end{abstract}

JEL Code: D81, D92, E32.

Keywords: business cycles, real options, investment, Markov switching, Tobin's $q$, uncertainty.

\author{
$\mathrm{Yu}-\mathrm{Fu}$ Chen \\ Economic Studies \\ School of Social \& Environmental Sciences \\ University of Dundee \\ Dundee DD1 4HN \\ United Kingdom \\ y.f.chen@dundee.ac.uk
}

\author{
Michael Funke \\ Department of Economics \\ Hamburg University \\ Von-Melle-Park 5 \\ 20146 Hamburg \\ Germany \\ funke@econ.uni-hamburg.de
}

Dundee \& Hamburg, June 2009

We are grateful to Giuseppe Bertola for his valuable comments and suggestions. Furthermore, we appreciate helpful comments on earlier versions of the paper from seminar participants at the Annual Meeting of the Money, Macro and Finance Group, a Bank of England Research Seminar, the Annual Symposium of the Society for Nonlinear Dynamics and Econometrics and the CESifo Summer Institute Workshop in Venice. Remaining errors are ours. 


\section{Introduction}

The wave of financial crisis across advanced economies and emerging market countries has brought to the fore a number of issues, many of which have important implications for economic policy. Among these is the issue that uncertainty may lead to prudence, if not outright paralysis, on the part of investors and firms. Referring to the current financial crisis, Blanchard (2009) offers the following observation: "Crisis feeds uncertainty. And uncertainty affects behaviour, which feeds the crisis. Were a magic wand to remove uncertainty, the next few quarters would still be tough (...), but the crisis would largely go away". This is quite an apt description of the financial crisis and there is not much to add to this statement.

Modelling the uncertainty-investment nexus using real options has gained widespread appeal in recent years. Corporate investment opportunities may be represented as a set of real options to acquire physical capital. As argued by Dixit and Pindyck (1994, p. 3) "most investment decisions share three important characteristics, investment irreversibility, uncertainty and the ability to choose the optimal timing of investment”. Managers are aware that investment is an opportunity and not an obligation. This causes them to behave as if they own option-rights. Moreover they know that, due to partial irreversibility, the exercise of their option rights reduces flexibility. As a result, the optimal time to kill the option is well after the point at which expected discounted future cash flow equals the cost of investment and firms may prefer a wait-and-see attitude even when they are risk-neutral. In volatile environments in which new information is arriving, the best tactic may be to keep options open and await new information rather than commit to an investment today. ${ }^{1}$ This appealing modelling approach can thus enrich theory by clarifying issues concerning the "when" of investments.

In the real options literature it is widely assumed that the present values of cash flows generated by the capital stock are uncertain and that their evolution can be described by stochastic processes. Consequently, the literature on investment under uncertainty uses options-based models and option pricing techniques to study investment decisions. An appropriate identification of the optimal exercise strategies for real options plays a crucial part in the maximization of a firm's market value. So far, however, the real options literature provides relatively little insight into the impact of business cycles on the investment decisions of firms. Most of the time, authors assume that the entire (exogenous) uncertainty in the economy can be described by a geometric Brownian motion process which is unsystematic across firms. It is, however, much more realistic to model an economy which is subject to macroeconomic shocks and business cycle fluctuations. The impact of business cycles on investment activity is well-documented but remains under-studied in the real options literature. Consequently, our aim in this paper is to enrich the stream of literature on real options by

\footnotetext{
${ }^{1}$ The literature on real options has been developing rapidly over the past decade. Reviews of this burgeoning literature are provided in Dixit and Pindyck (1994) and Stokey (2008). Both books remain major benchmarks.
} 
incorporating both qualitative and quantitative aspects of business cycle fluctuations and financial turmoil periods. ${ }^{2}$ We assume that demand shifts stochastically between three different states, each with different rates of drift and volatility. ${ }^{3}$ The setting assumes that the shifts are governed by a three-state Markov switching model with constant transition probabilities. ${ }^{4}$ We believe that the bulk of real options models used to date - and which don't include any such abrupt nonlinear processes - will not be able to alert policymakers to the importance of abrupt nonlinear behaviours.

The layout of the paper is as follows. In section 2 we develop a stylized options-based model of investment under cyclical uncertainty. Section 3 contains an in-depth numerical analysis and interpretation of our results. The final section of the paper summarizes some key findings and draws out some policy implications.

\section{A Model of (Partially) Irreversible Investment with Fluctuating Risk}

Now we proceed to formally setup and solve the model, including technical details and derivations. Our starting point is Abel and Eberly's (1994) model of irreversible investment, which is a flexible and tractable example of the options-based models, and can be readily generalized to include cyclical uncertainty. We place standard assumptions on the production function of the representative firm to guarantee that the firm's problem is well-behaved. The Cobb-Douglas production function is given by

$$
Y_{t}=K_{t}^{\alpha} N^{1-\alpha}, \quad 0<\alpha<1,
$$

where $K$ is the capital stock, $N$ is the constant employment level, and $\alpha$ is a parameter determining the shares between capital and labour in production. The employment $N$ is taken as given at any point in time, giving rise to strict concavity of the production function. It is assumed that the firm faces a stochastic isoelastic demand function

$$
p=Y_{t}^{(1-\psi) / \psi} Z_{t}, \quad \psi \geq 1
$$

\footnotetext{
${ }^{2}$ See Cooley (1995) for a detailed discussion of why quantitative implications of a theory are as important as the qualitative counterpart.

${ }^{3}$ The application of real options theory to business cycles is a relatively recent development. The papers closest to this paper are the one's by Hassler (1996) and Guo et al. (2005). By including a third regime for periods of financial turmoil, we depart from their analysis and add another layer of complexity to the literature. We think that using a three regime model improves our ability to model the current financial turmoil period and provides a more comprehensive picture of the relative likelihood of different future investment trajectories than previously available. Another advantage of introducing a third regime is that information on low-probability highconsequence events allows investors to account for risk-aversion in their choices.

${ }^{4}$ In our setup the firms are not aware of future business cycle turning points but they know the probability distribution Alternatively, Bagliano and Bertola (2004, p. 113 and pp. 244-245) have also discussed a stylised
} 
where $p$ denotes the price, $Y$ is output, $Z$ denotes the random demand shock, and $\psi$ is an elasticity parameter that takes its minimum value of 1 in a perfectly competitive environment. Therefore, current profits, measured in units of output, are defined as

$$
\Pi=Z_{t} K_{t}^{\alpha_{1}} N^{\alpha_{2}}-\operatorname{Cost}\left(I_{t}\right)-x K_{t}-w N,
$$

where $\alpha_{1}=\alpha / \psi$ and $\alpha_{2}=(1-\alpha) / \psi, I_{t}$ is gross investment, $x$ denotes constant service expenses for capital, $w$ is the constant real wage, and $\operatorname{Cost}(\cdot)$ are the total investment expenditures denoted by the following functions:

$$
\operatorname{Cost}\left(I_{t}\right)= \begin{cases}p_{K}^{+} I_{t}+\frac{1}{2} \gamma_{t}^{2} & \text { for } I_{t}>0 \\ 0 & \text { for } I_{t}=0 \\ p_{K}^{-} I_{t}+\frac{1}{2} \gamma_{t}^{2} & \text { for } I_{t}<0\end{cases}
$$

Purchase (resale) costs are the costs of buying (selling) capital. Let $p_{K}^{+}\left(p_{K}^{-}\right)$be the price per unit of investment good at which the firm can buy (sell) any amount of capital. We assume that $p_{K}^{+} \geq p_{K}^{-} \geq 0 .{ }^{5}$ Adjustment costs, $\gamma_{t}^{2} / 2$, are continuous and strictly convex in $I$, and $\gamma$ is a positive parameter. There are at least two stylized facts in the data that supports the presence of convex costs. First, in the absence of convex adjustment costs, the firm adjusts capital balance instantaneously at an infinite rate and the variables are never outside the no-investment region. Clearly, it is difficult to imagine firms investing at an infinite rate in the real world. Second, if firms face only linear costs, their marginal $q$ will never be above the cost of one unit of capital, $p_{K}^{+}$. If convex costs are considered, then it is possible to have $q_{t}>p_{K}^{+}$. Considering the depreciation of capital, the adjustment of capital over time is denoted by

$$
\frac{d K_{t}}{d t}=I_{t}-\delta K_{t}
$$

model of factor demand under perfectly predictable cycles by assuming that the cyclical index is given by a deterministic trigonometric function of time which repeats itself every $\pi=3.1415$ units of time.

${ }^{5}$ Thus, we relax the assumption that investment be irreversible. Instead we assume that reversibility is a continuous rather than a dichotomous concept. The assumption of complete irreversibility is given by $p_{K}^{-}=0$. Investments that are largely reversible include those that do not depreciate, those that have many uses, or those that are traded in efficient secondary markets. Often, however, as buyers in second hand markets are unable to evaluate the quality of an item they will offer a price lower than the market one. This "lemons" problem then 
where $\delta$ represents the constant depreciation rate. To capture probabilistic state transitions over time, Markov-switching models popularized by Hamilton $(1989,1990)$ provide an attractive analytical framework. The notable characteristic of such models is the assumption that the unobservable realization of the states is governed by a discrete-time, discrete state Markov stochastic process with fixed transition probabilities and state-dependent variances. In other words, it is time itself and not the state of the economic environment that governs turning points. ${ }^{6}$

A key step in the modelling stage is the specification of the number of regimes. Before embarking on the modelling exercise, we first try to detect different regimes. In order to determine the number of regimes, we use the Chicago Board Options Exchange (CBOE) volatility indices. The volatility indices show the market's expectation of 30-day volatility. The VIX index is constructed using the implied volatilities of a wide range of S\&P 500 index options. The VBO index shows the implied volatility of a range of S\&P 100 index options. The calculated volatilities are meant to be forward looking and are calculated from both calls and puts. Perhaps one of the most valuable features of the indices is the existence of more than 20 years of historical prices. This extensive data set provides economists with a useful perspective of how option prices and uncertainty have behaved in response to a variety of market conditions. Both indices of stock market volatility are widely used measures of market risk and are often referred to as the "investor fear gauge".

Figure 1: CBOE Volatility Indices VIX and VBO

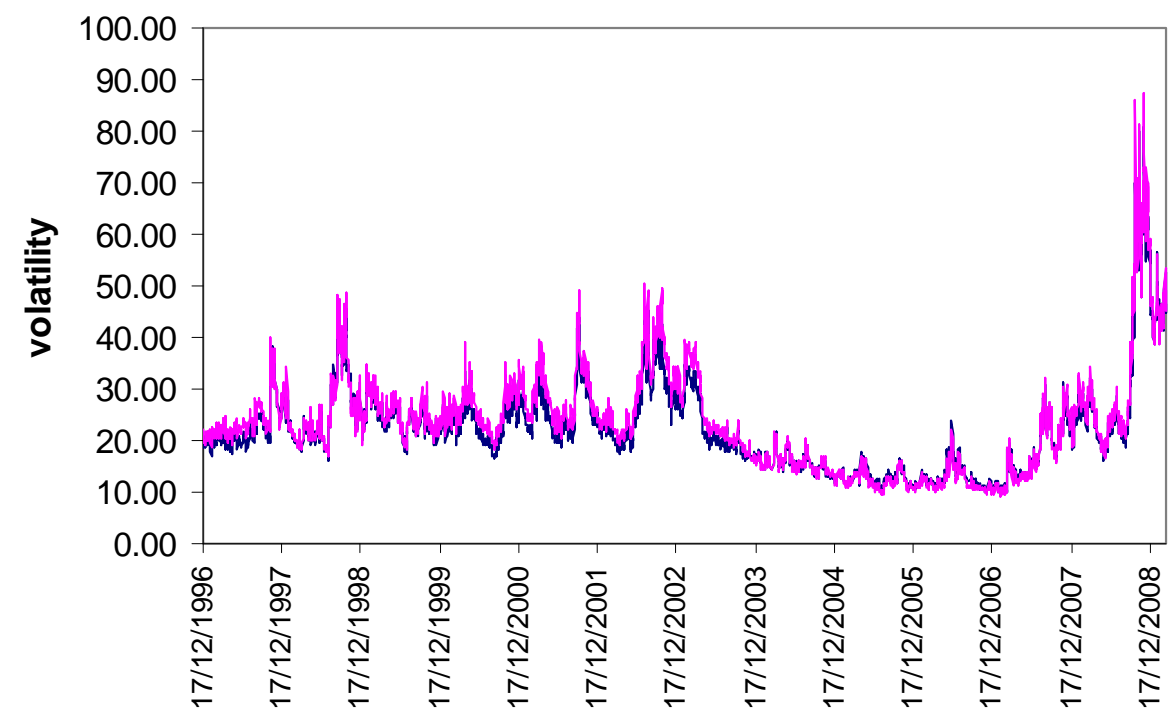

Source: Chicago Board Options Exchange; see http://www.cboe.com/micro/vix/introduction.aspx.

becomes the cause of partial irreversibility of many investments even when the assets are not firm or industry specific.

${ }^{6}$ Markov-switching models with constant transition probabilities have been applied to interest rates [Hamilton (1988)], the behaviour of GNP [Hamilton (1989)], stock returns [Cecchetti et al. (1990)], and floating exchange rates [Engel and Hamilton (1990)]. 
Although there is no perfect correspondence between cyclical phases and regimes, apparently two regimes (booms vs. recessions) have existed between 1996 and 2007. In contrast, volatility is at an alltime high during the current financial crisis. When the financial system was on the brink of collapse in September 2008, economies have experienced panic and despair. Many banks faced major problems in terms of liquidity shortages and many bad loans. Additionally, the large bancassurance groups and multinational insurers (i.e. AIG) faced major write-offs. Many have considered the opaqueness of the financial markets and the excessive risk-taking by banks and other market participants as the main causes of the crisis. Supervisory arrangements have not been able to keep up with the fast pace of financial innovation and the associated risk-taking and information asymmetries.

The depth of the current recession suggests the existence of a third regime indicating episodes of financial turmoil and sharp contractions. Contrary to shallow recessions, episodes of financial turmoil are associated with severe and protracted downturns. We don't reserve the word "depression” for the current situation because the financial crisis doesn't match in severity the Great Depression of the 1930s. ${ }^{7}$

Given the evidence in Figure 1, we propose a nonlinear analytical framework with three stochastic regimes for the risk level (two recessionary states and one expansionary state). This setup embeds the above arguments. ${ }^{8}$ We assume that the demand process follows the continuous-time stochastic (geometrical Brownian motion) Markov switching processes

$$
d Z_{t}=\eta_{i} Z_{t} d t+\sigma_{i} Z_{t} d W_{t}, \quad \text { for } i=0,1,2
$$

where $d W_{t}=\varepsilon_{t} \sqrt{d t}$ denotes the increments of a standard Wiener process, $\varepsilon_{t}$ is an i.i.d. sequence with mean zero and a standard deviation of unity, $\eta_{i}$ is the drift parameter, and $\sigma_{i}^{2}$ the variance parameter. It is assumed that if the boom (state 2) occurs, the drift and the variance parameters are $\eta_{2}$ and $\sigma_{2}^{2}$ respectively; if the recession state (state 1 ) emerges, they are $\eta_{1}$ and $\sigma_{1}^{2}$, respectively; and if the

\footnotetext{
${ }^{7}$ The introduction of a third regime is a refreshing move reflecting that the research agenda associated with the Great Moderation and the consensus it produced is increasingly coming under question. Sichel (1994) and Ferrara (2003) have also expressed doubts as to whether business cycles can adequately be characterized by a binary Markov-switching model. They have therefore proposed more realistic three-regime settings for the US economy.

${ }^{8}$ Some words of caution have to be spent on the Markov-switching approach to business cycles. In the Markovswitching approach, no a priori definition of business cycle is imposed. By means of the setup, different regimes are calibrated, indeed these regimes differ in terms of average growth rates and/or growth volatilities. Actually, the modelling approach simply represents the idea that economic growth is characterised by different phases. Even if the assumed three regimes and the true phases of the cyclical growth process may not be perfectly related, we can consider this specification as a local approximation.
} 
financial turmoil state (state 0 ) occurs, the parameters are given by $\eta_{0}$ and $\sigma_{0}^{2}$, respectively. ${ }^{9}$ It is expected that the value of the drift (growth of demand) of the state 2 is higher than the one of the states 1 and 0 , i.e. $\eta_{2}>\eta_{1}>\eta_{0}$ holds. The corresponding volatility parameters are in the opposite order $\sigma_{0}>\sigma_{1}>\sigma_{2}$.

The next aim is to describe the connections between the phases of cycles. We propose the following $3 \times 3$ transition matrix providing information on how business cycle phases are related.

$$
\left[\begin{array}{ccc}
1-\theta \Delta t & 0 & \theta \Delta t \\
0 & 1-\phi \Delta t & \phi \Delta t \\
\lambda_{0} \Delta t & \lambda_{1} \Delta t & 1-\lambda_{0} \Delta t-\lambda_{1} \Delta t
\end{array}\right] \text {, }
$$

where $\lambda_{0}\left(\lambda_{1}\right)$ denotes the probability of changing from boom state to financial turmoil state (recession state). Correspondingly, $\phi(\theta)$ represents the transition probability from recession state (financial turmoil state) to boom state. It is assumed that there are no transitions between recession state and the financial turmoil state. ${ }^{10}$ This constraint based on simple economic considerations simplifies the analysis significantly.

The combination of firm-specific shocks and three macroeconomic regimes reflects the importance of idiosyncratic and aggregate uncertainty. The importance of idiosyncratic uncertainty is consistent with recent microeconometric research examining the factors behind productivity growth. A striking finding of this literature is the magnitude of heterogeneity across firms which imply that idiosyncratic factors in firm-level outcomes dominate the pace of investment, reallocation and job creation in an economy. Another key pattern in the behaviour of firm-level reallocation, investment and productivity is that the pace varies cyclically, i.e. the data provides evidence on synchronisation/staggering of creation/destruction. ${ }^{11}$ Both facts provided a motivation for the modelling framework presented here. The firm chooses its optimal level of investment over time to maximise the intertemporal value of profits, subject to the capital stock accumulation [equation (5)] and the stochastic Markov switching processes [equation (6)]. Thus, the firm's profit-maximisation problem is denoted by:

\footnotetext{
${ }^{9}$ Recall that Hamilton (1989) has assumed state-independent variances. The two-state Markov chain allows agents' sentiments to switch from one state to another in a manner reminiscent of Keynes' "animal spirits". Although the modelling approach is given exogenously - and thus it may be considered ad hoc - it allows us to assess the investment reactions to cyclical uncertainty generated by different underlying conceptual models.

${ }^{10}$ History suggests that balance-sheet recessions are sometimes long and that the recoveries which follow are feeble because firms and households must painfully rebuild their balance-sheets. Despite the anxiety that has aroused, we assume a V-shaped („trampoline-type“) vibrant rebound after a financial turmoil. We leave the investigation of alternative specifications to future work.

${ }^{11}$ Excellent surveys of this literature are available in Bartelsman and Doms (2000) and Haltiwanger (2000). Caballero and Engel (1993) and Caballero et al. (1995) have recently proposed frameworks to discuss the distinction between idiosyncratic and aggregate shocks, and the potentially contrasting implications of these shocks to the dynamics of aggregate variables. Their results suggest that idiosyncratic shocks tend to smooth out
} 
(8) $V=\max _{I_{t}} E\left[\int_{0}^{\infty}\left[Z_{t} K_{t}^{\alpha_{1}} N^{\alpha_{2}}-x K_{t}-w N-\operatorname{Cost}\left(I_{t}\right)\right] e^{-r t} d t \mid Z=Z_{0}, K=K_{0}\right]$ s.t. (4), (5) and (6),

where $r$ is the discount rate. ${ }^{12}$ For simplicity the firm has an infinite lifetime. We maintain the standard assumption that investors are risk-neutral. ${ }^{13}$

Applying Ito's Lemma, the stochastic nature of this optimization problem requires the solution to the following Bellman equations for the states 0, 1 and 2:

$$
\begin{gathered}
r V_{0}=\max _{I}\left[Z K^{\alpha_{1}} N^{\alpha_{2}}-x K-w N-\operatorname{Cost}(I)+V_{0 K}(I-\delta K)\right. \\
\left.+\eta_{0} Z V_{0 Z}+\sigma_{0}^{2} Z^{2} V_{0 Z Z} / 2+\theta\left(V_{2}-V_{0}\right)\right] \\
r V_{1}=\max _{I}\left[Z K^{\alpha_{1}} N^{\alpha_{2}}-x K-w N-\operatorname{Cost}(I)+V_{1 K}(I-\delta K)\right. \\
\left.+\eta_{1} Z V_{1 Z}+\sigma_{1}^{2} Z^{2} V_{1 Z Z} / 2+\phi\left(V_{2}-V_{1}\right)\right], \\
r V_{2}=\max _{I}\left[Z K^{\alpha_{1}} N^{\alpha_{2}}-x K-w N-\operatorname{Cost}(I)+V_{2 K}(I-\delta K)\right. \\
\left.+\eta_{2} Z V_{2 Z}+\frac{1}{2} \sigma_{2}^{2} Z^{2} V_{2 Z Z}+\lambda_{0}\left(V_{0}-V_{2}\right)++\lambda_{1}\left(V_{1}-V_{2}\right)\right]
\end{gathered}
$$

where $V_{0}, V_{1}$, and $V_{2}$ represent the value of the firm in the states 0,1 , and 2 respectively. The nature of the solution of this problem is now intuitive. The investment policy that maximizes profits has a simple and intuitive form: the $q$-type investment function for $I$ for the states 0,1 and 2 is denoted by

$$
p_{K}^{+/-}+\gamma=q_{i},
$$

where $q_{i}=V_{i K}$ for $i=0,1,2$. In effect, the capital stock is assumed to be continuously divisible, so that investment can be undertaken up to the point at which it becomes unprofitable. It is intuitive to comprehend that in boom state, the $q$ value is higher due to higher growth rate of demand and lower

microeconomic rigidities, while aggregate shocks (for example, business cycle fluctuations) tend to coordinate individual firms' actions.

${ }^{12}$ Note that the employment level is assumed a constant. Eberly and van Mieghem (1997) and Chen and Funke (2008) examine interrelated employment and investment decisions in a real options modelling framework.

${ }^{13}$ For a risk-averse firm, the certainty equivalent is always less than the mean because losses relative to the mean reduce utility more than equal profits above the mean. Risk aversion may be accommodated by assuming that the firm is a mean-variance optimizer, attempting to maximize the utility function $\Pi^{*}=\{E(\Pi)-\varepsilon \sigma \Pi\}$, where $\Pi$ are profits, $\sigma$ is the standard deviation of profits, and risk aversion is captured by allowing $\varepsilon>0$. 
risk so that the firm undertake more investment on average. On the other hand, the firm would naturally have lower $q$ values and reduce investment activities.

The first-order-condition (12) shows the optimal value of investment and Tobin's $q$ in terms of stochastic $Z$ and the adjustment cost parameter $\gamma$. The $q$ value is equal to purchasing/selling price of capitals when there is no investment $(I=0)$. However, due to the fluctuations of demand $Z$ and noninstant adjustment of investment (finite value of the quadratic adjustment cost parameter $\gamma$ ), the $q$ values can deviate from the purchasing/selling price along the optimal path of investment. In the situation where the purchasing price corresponds to the re-selling price $p_{K}^{+}=p_{K}^{-}=p_{K}$, any positive (or negative) fluctuations in $Z$ lead to an increase (or decrease) in $q$ and hence $q$ can be higher (or lower) than $p_{K}$ for some time until $K$ increases (or decreases) via equation (5). Note that an increase (or decrease) in $K$ will lower (raise) marginal $q$ so that $q$ will reverse to its optimal value $p_{K}$ over time until further fluctuations in $Z$ are realised. In the situation where the purchasing price is greater than the re-selling price $p_{K}^{+}>p_{K}^{-}$, a region of inactivity $p_{K}^{+}>q>p_{K}^{-}$within which firms don't invest arises. Within this area, firms choose not to purchase (sell) capitals as long as the fluctuations of $Z$ do not cause marginal $q$ to leave the limits of the inaction area. Note that it is quite impossible for the firm to stay in the inaction area for a long time even with small fluctuations in demand $Z$. However, the depreciation of the capital stock $K$ will raise the $q$ value above $p_{K}^{+}$eventually.

Note that the processes $q_{0}(Z)$ in state 0 (turmoil), $q_{1}(Z)$ in state 1 (recession), and $q_{2}(Z)$ in state 2 (boom) are regulated. In state 0 , as the demand shock $Z$ hits the (dis-)investment threshold, the firm start buying (selling) new (old) capital. Note that within the inaction area: $p_{K}^{-}<q_{0}<p_{K}^{+}$, the firm undertakes no investment or disinvestment in state 2. The same logic also applies to state 1 and 2 so that the firms do nothing whenever $p_{K}^{-}<q_{1}<p_{K}^{+}$or $p_{K}^{-}<q_{2}<p_{K}^{+}$. Therefore we have three coupled regulated stochastic processes for $q_{0}, q_{1}$ and $q_{2}$ for the thresholds, which are defined in Table 1 . However, $q_{0}, q_{1}$ and $q_{2}$ may be driven outside the zone of zero investment if $\gamma>0$. Investment will tend to bring it back inside depending on the value of $\gamma$, but the process is not instantaneous.

Table 1: The $Z$ Thresholds for Booms, Recessions, and Financial Turmoil and their Corresponding $q$ Values

\begin{tabular}{|c|c|c|c|c|c|c|}
\hline & \multicolumn{2}{|c|}{ State 2 (boom) } & \multicolumn{2}{|c|}{ State 1 (recession) } & \multicolumn{2}{|c|}{ State 0 (turmoil) } \\
\hline & Investment & Disinvestment & Investment & Disinvestment & Investment & Disinvestment \\
\hline Thresholds & $Z_{2}^{+}$ & $Z_{2}^{-}$ & $Z_{1}^{+}$ & $Z_{1}^{-}$ & $Z_{0}^{+}$ & $Z_{0}^{-}$ \\
\hline $\begin{array}{c}\text { The values } \\
\text { of } q\end{array}$ & $\begin{array}{l}q_{2}\left(Z_{2}^{+}\right) \\
=p_{K}^{+}\end{array}$ & $\begin{array}{l}q_{2}\left(Z_{2}^{-}\right) \\
=p_{K}^{-}\end{array}$ & $\begin{array}{l}q_{1}\left(Z_{1}^{+}\right) \\
=p_{K}^{+}\end{array}$ & $\begin{array}{l}q_{1}\left(Z_{1}^{-}\right) \\
=p_{K}^{-}\end{array}$ & $\begin{array}{l}q_{0}\left(Z_{0}^{+}\right) \\
=p_{K}^{+}\end{array}$ & $\begin{array}{l}q_{0}\left(Z_{0}^{-}\right) \\
=p_{K}^{-}\end{array}$ \\
\hline
\end{tabular}


The inaction areas for states 0,1 , and 2 are defined for $p_{K}^{-} \leq q_{0} \leq p_{K}^{+}, p_{K}^{-} \leq q_{1} \leq p_{K}^{+}$, and $p_{K}^{-} \leq q_{2} \leq p_{K}^{+}$, respectively. Note that there are no investment and dis-investment activities for the firm whose $q$ values are inside those inaction areas. Another worth noting point is that the six thresholds $\left(Z_{2}^{+}, Z_{2}^{-}, Z_{1}^{+}, Z_{1}^{-}, Z_{0}^{+}\right.$and $\left.Z_{0}^{-}\right)$are moving thresholds that change over time as $K$ changes due to depreciation, investment, and/or dis-investment. For example, assume that the value of $Z$ is within the thresholds initially. When $K$ depreciates, the value of $q$ will rise even when the firm undertakes no investment/disinvestment. The rising $q$ value then leads to lower thresholds over time. This implies that with moderate depreciation, the firm will seldom undertake disinvestment. ${ }^{14}$

By substituting $\left(I=\left(q_{i}-p_{K}^{+--}\right) / \gamma\right)$ back into the Bellman equations (9), (10), and (11) and rearranging we can obtain the equations for solving Tobin's $q$ and the particular solutions and homogenous solutions for $q$.

The solutions for $q_{0}, q_{1}$ and, $q_{2}$ all consist of particular solutions and general solutions so that $q_{0}=q_{0}^{P}+q_{0}^{G}, q_{1}=q_{1}^{P}+q_{1}^{G}, q_{2}=q_{2}^{P}+q_{2}^{G}$. It is shown in the Appendix that the particular solutions for $q_{0}, q_{1}$, and $q_{2}$ are represented by:

$$
\begin{aligned}
& q_{0}^{P}=a_{0} Z K^{\alpha_{1}-1} N^{\alpha_{2}}-\frac{x}{r+\delta}, \\
& q_{1}^{P}=a_{1} Z K^{\alpha_{1}-1} N^{\alpha_{2}}-\frac{x}{r+\delta}, \\
& q_{2}^{P}=a_{3} Z K^{\alpha_{1}-1} N^{\alpha_{2}}-\frac{x}{r+\delta},
\end{aligned}
$$

where the coefficients $a_{0}, a_{1}$, and $a_{2}$ follow (A19) - (A21) in the Appendix. And the general solutions for $q_{0}, q_{1}$, and $q_{2}$ represent the net value of options and are

$$
\begin{aligned}
& \text { (16) } q_{0}^{G}=-\sum_{i=1}^{3} A_{i}\left(Z K^{\alpha_{1}-1}\right)^{\beta_{i}}+\sum_{i=4}^{6} A_{i}\left(Z K^{\alpha_{1}-1}\right)^{\beta_{i}} \\
& \text { (17) } q_{1}^{G}=-\sum_{i=1}^{3} B_{i}\left(Z K^{\alpha_{1}-1}\right)^{\beta_{i}}+\sum_{i=4}^{6} B_{i}\left(Z K^{\alpha_{1}-1}\right)^{\beta_{i}} \\
& \text { (18) } q_{2}^{G}=-\sum_{i=1}^{3} C_{i}\left(Z K^{\alpha_{1}-1}\right)^{\beta_{i}}+\sum_{i=4}^{6} C_{i}\left(Z K^{\alpha_{1}-1}\right)^{\beta_{i}}
\end{aligned}
$$

\footnotetext{
${ }^{14}$ This is echoed by the empirical work of Ramey and Shapiro (1998) showing that the prices of used capital are too low so that firms seldom scrap capitals.
} 
where $\beta_{1}>\beta_{2}>\beta_{3}>0>\beta_{4}>\beta_{5}>\beta_{6}$ and they are the six characteristic roots of the following equation for $\beta$. It can be noted that the positive $\beta$ terms of (16)-(18) are generally related to investment options and the negative $\beta$ terms are linked to disinvestment terms. ${ }^{15}$

$$
\begin{aligned}
& \left(r+\delta+\delta \beta\left(\alpha_{1}-1\right)-\eta_{2} \beta-\frac{1}{2} \sigma_{2}^{2} \beta(\beta-1)+\lambda_{0}+\lambda_{1}\right)\left(r+\delta+\delta \beta\left(\alpha_{1}-1\right)-\eta_{0} \beta-\frac{1}{2} \sigma_{0}^{2} \beta(\beta-1)+\theta\right) \\
& \times\left(r+\delta+\delta \beta\left(\alpha_{1}-1\right)-\eta_{1} \beta-\frac{1}{2} \sigma_{1}^{2} \beta(\beta-1)+\phi\right)=\theta \lambda_{0}\left(r+\delta+\delta \beta\left(\alpha_{1}-1\right)-\eta_{1} \beta-\frac{1}{2} \sigma_{1}^{2} \beta(\beta-1)+\phi\right) . \\
& +\phi \lambda_{1}\left(r+\delta+\delta \beta\left(\alpha_{1}-1\right)-\eta_{0} \beta-\frac{1}{2} \sigma_{0}^{2} \beta(\beta-1)+\theta\right) .
\end{aligned}
$$

Note that the relationships between $A_{i}, B_{i}$, and $C_{i}$ are according to the following equations:

$$
A_{i} \frac{\left(r+\delta+\delta \beta\left(\alpha_{1}-1\right)-\eta_{0} \beta-\frac{1}{2} \sigma_{0}^{2} \beta(\beta-1)+\theta\right)}{\theta}=C_{i}, i=1, \ldots, 6
$$

$$
B_{i} \frac{\left(r+\delta+\delta \beta\left(\alpha_{1}-1\right)-\eta_{1} \beta-\frac{1}{2} \sigma_{1}^{2} \beta(\beta-1)+\phi\right)}{\phi}=C_{i}, i=1, \ldots, 6
$$

The set of boundary conditions that applies to this optimal stopping problem is composed by the value matching conditions ${ }^{16}$

$$
\begin{aligned}
& q_{0}\left(Z_{0}^{+}, A_{1}, A_{2}, A_{3}, A_{4}, A_{5}, A_{6}\right)=q_{0}^{P}\left(Z_{0}^{+}\right)+q_{0}^{G}\left(Z_{0}^{+}, A_{1}, A_{2}, A_{3}, A_{4}, A_{5}, A_{6}\right)=p_{K}^{+}, \\
& q_{0}\left(Z_{0}^{-}, A_{1}, A_{2}, A_{3}, A_{4}, A_{5}, A_{6}\right)=q_{0}^{P}\left(Z_{0}^{-}\right)+q_{0}^{G}\left(Z_{0}^{-}, A_{1}, A_{2}, A_{3}, A_{4}, A_{5}, A_{6}\right)=p_{K}^{-}, \\
& q_{1}\left(Z_{1}^{+}, B_{1}, B_{2}, B_{3}, B_{4}, B_{5}, B_{6}\right)=q_{1}^{P}\left(Z_{1}^{+}\right)+q_{1}^{G}\left(Z_{1}^{+}, B_{1}, B_{2}, B_{3}, B_{4}, B_{5}, B_{6}\right)=p_{K}^{+}, \\
& q_{1}\left(Z_{1}^{-}, B_{1}, B_{2}, B_{3}, B_{4}, B_{5}, B_{6}\right)=q_{1}^{P}\left(Z_{1}^{-}\right)+q_{1}^{G}\left(Z_{1}^{-}, B_{1}, B_{2}, B_{3}, B_{4}, B_{5}, B_{6}\right)=p_{K}^{-}, \\
& q_{2}\left(Z_{2}^{+}, C_{1}, C_{2}, C_{3}, C_{4}, C_{5}, C_{6}\right)=q_{2}^{P}\left(Z_{21}^{+}\right)+q_{2}^{G}\left(Z_{2}^{+}, C_{1}, C_{2}, C_{3}, C_{4}, C_{5}, C_{6}\right)=p_{K}^{+}, \\
& q_{2}\left(Z_{2}^{-}, C_{1}, C_{2}, C_{3}, C_{4}, C_{5}, C_{6}\right)=q_{1}^{P}\left(Z_{2}^{-}\right)+q_{1}^{G}\left(Z_{2}^{-}, C_{1}, C_{2}, C_{3}, C_{4}, C_{5}, C_{6}\right)=p_{K}^{-},
\end{aligned}
$$

and the corresponding smooth-pasting conditions

\footnotetext{
${ }^{15}$ We adopt a regulated process with three states. Thus, the analogy between the homogenous solutions and the option terms are stated loosely.

${ }^{16}$ The value-matching conditions here are different from Driffill et al. (2003). They use a financial explanation and approach to solve the system. In this paper, a direct mathematical approach of regulated stochastic processes of $q$ value is used to solve the system.
} 


$$
\begin{aligned}
& \frac{\partial q_{0}\left(Z_{0}^{+}, A_{1}, A_{2}, A_{3}, A_{4}, A_{5}, A_{6}\right)}{\partial Z_{0}^{+}}=0, \\
& \frac{\partial q_{0}\left(Z_{0}^{-}, A_{1}, A_{2}, A_{3}, A_{4}, A_{5}, A_{6}\right)}{\partial Z_{0}^{-}}=0, \\
& \frac{\partial q_{1}\left(Z_{1}^{+}, B_{1}, B_{2}, B_{3}, B_{4}, B_{5}, B_{6}\right)}{\partial Z_{1}^{+}}=0, \\
& \frac{\partial q_{1}\left(Z_{1}^{-}, B_{1}, B_{2}, B_{3}, B_{4}, B_{5}, B_{6}\right)}{\partial Z_{1}^{-}}=0, \\
& \frac{\partial q_{2}\left(Z_{2}^{+}, C_{1}, C_{2}, C_{3}, C_{4}, C_{5}, C_{6}\right)}{\partial Z_{2}^{+}}=0, \\
& \frac{\partial q_{2}\left(Z_{2}^{-}, C_{1}, C_{2}, C_{3}, C_{4}, C_{5}, C_{6}\right)}{\partial Z_{2}^{-}}=0 .
\end{aligned}
$$

Making use of the value-matching and smooth-pasting conditions, we get the boundary values that separate the space into two regions: one where it is optimal to exercise the investment option and another where it is not.

The solution of the model is straightforward. There are 24 unknown variables: three investment thresholds, $Z_{2}^{+}, Z_{1}^{+}, Z_{0}^{+}$, three disinvestment thresholds, $Z_{2}^{-}, Z_{1}^{-}, Z_{0}^{-}$, eighteen coefficients for options terms, $A_{i}, B_{i}, C_{i}$ and 24 equations: (22) (33) for value-matching and smooth-pasting conditions and 12 relationships in equations (20) and (21). In the next section, the model is parameterized and used to gauge the magnitude of the link between cyclical uncertainty and investment.

\section{Model Simulations}

Section 2 has carefully developed and discussed the main features of the model. Unfortunately, the model has no closed form solution. This means that we need to use extensive numerical illustrations to gain further insight into the results of the previous section to have a "feel" for the model. The most important goal of these simulations is to see how certain crucial aspects of the model react to changes in parameters. In order to simulate the model, we need to cross the "minefield" of calibration. As methodological issues related to calibration are not the focus of this paper, a pragmatic stance is taken. The unit time length corresponds to one year. Where possible, parameter values are drawn from empirical studies. Our base parameters which were chosen for realism are $\sigma_{0}=0.35, \sigma_{1}=0.25, \sigma_{2}=$ 0.15, $\eta_{0}=-0.04, \eta_{1}=0.01, \eta_{2}=0.025, \delta=0.07, \psi=1.5, \alpha=0.3, \theta=0.33, \phi=0.15, p_{K}^{+}=1.0$, $p_{K}^{-}=0.4, r=0.05, x=0.1$ and $K_{0}=N_{0}=1.0$. The price elasticity of demand parameter is set at $\psi=$ 
1.50 as in Bovenberg et al. (1998). Choosing values for $\sigma_{0}, \sigma_{1}$ and $\sigma_{2}$ requires care, since these parameters determine the amplitude of the business cycles and underpin the link between cyclical uncertainty and investment. Even more significant is the fixing of the switching probabilities. The set of turning points needs to meet several criteria to match the definition and features of a business cycle. These criteria include peaks and troughs that alternate and minimum durations of recessions and boom periods. We set the baseline standard switching probabilities $\theta=0.25, \phi=0.4, \lambda_{0}=0.02$ and $\lambda_{0}=0.1$, respectively. Hence, the expected duration for booms is $\left(1-\lambda_{0}-\lambda_{1}\right) /\left(\lambda_{0}+\lambda_{1}\right)=0.88 / 0.12=$ 7.3 years. The expected duration of a recession is $(1-\phi) / \phi=0.6 / 0.4=1.5$ years, and the expected duration of a period of financial turmoil is $(1-\theta) / \theta=0.75 / 0.25=3.0$ years. ${ }^{17}$

The main output of the model consists of thresholds that bisect the firm's decision-making space into zones where it is optimal to exercise the investment option and zones where the firm maximizes its value by leaving the option unexercised. We call these thresholds "bands of hysteresis". Within these bands, the yes-but-not-now-logic applies. To get some qualitative ideas of the impact exercised by the parameters of the model and to get a sense of the magnitudes, we give here some numerical calculations of the $Z$ investment thresholds (left panels) and $Z$ disinvestment thresholds (right panels) for a range of parameter values. In our first "reality check", we consider alternative switching probabilities. The results for alternative $\theta^{\prime}$ s and $\phi^{\prime}$ s are given in Figure 2 and 3.

The bands of hysteresis for alternative $\lambda_{0}$ and $\lambda_{1}$ parameters are plotted in Figure 4 and 5 . Several interesting observations warrant highlighting. First, the much larger investment threshold for turmoil periods indicates that the $3^{\text {rd }}$ regime has important ramifications for investment dynamics. This typifies Blanchard's (2009) assessment of risks. "When, as today, the unknown unknowns dominate, and the economic environment is so complex as to appear nearly incomprehensible, the result is extreme prudence, if not outright paralysis, on the part of investors, consumers and firms. And this behaviour, in turn, feeds the crisis." ${ }^{18}$ Given his description of the crisis in these terms, Blanchard (2009) advocates for policy to reinvigorate demand to help the economy to shift back. The numerical results provide a partial test of this statement and underscore the need to design models to account for potential nonlinear behaviour that could cause such state changes. The emergent property of the

\footnotetext{
${ }^{17}$ Business cycle fluctuations are characterized by an asymmetry in the duration of recessions and expansions with the latter lasting on average roughly 3-5 times as long as the former. For lessons for the current financial turmoil period and prospects for recovery, see International Monetary Fund (2008), pp. 129-158 and International Monetary Fund (2009), pp. 103-138. Cardarelli et al. (2009) have proposed an analytical framework to assess the impact of financial stress-in particular banking distress-on the real economy. It concludes that financial turmoil characterized by banking distress is more likely to be associated with severe and longer recessions than stress mainly in securities or foreign exchange markets. Economies with financial systems where a greater share of intermediation is channeled through securities markets rather than traditional relationship-based banking appear to be particularly vulnerable to sharp contractions, due to the greater procyclicality of leverage in their banking systems.

${ }^{18}$ Objective uncertainty is usually referred to as the "known unknowns". On the contrary, subjective uncertainty is about the "unknown unknowns". The subjective uncertainty view claims that with incomplete knowledge
} 
Markow-switching model considered is that smooth changes may not be valid for economic systems, especially when rapidly forced or substantially disturbed. Second, a rise in $\theta$ (the probability of jumping from turmoil to expansion) and rise in $\phi$ (the probability of jumping from recession to expansion) have small impacts on the investment and disinvestment thresholds. ${ }^{19}$

Figure 2: The Impact of $\theta$ Upon the $Z$ Thresholds
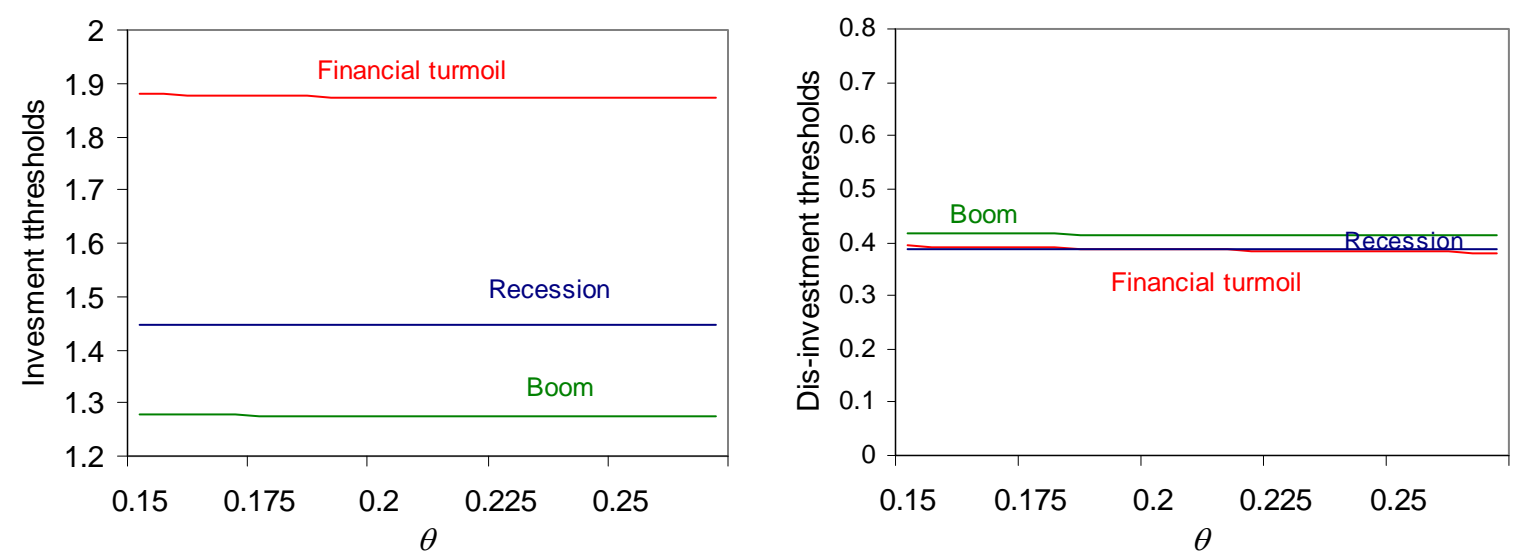

Figure 3: The Impact of $\phi$ Upon the $Z$ Thresholds
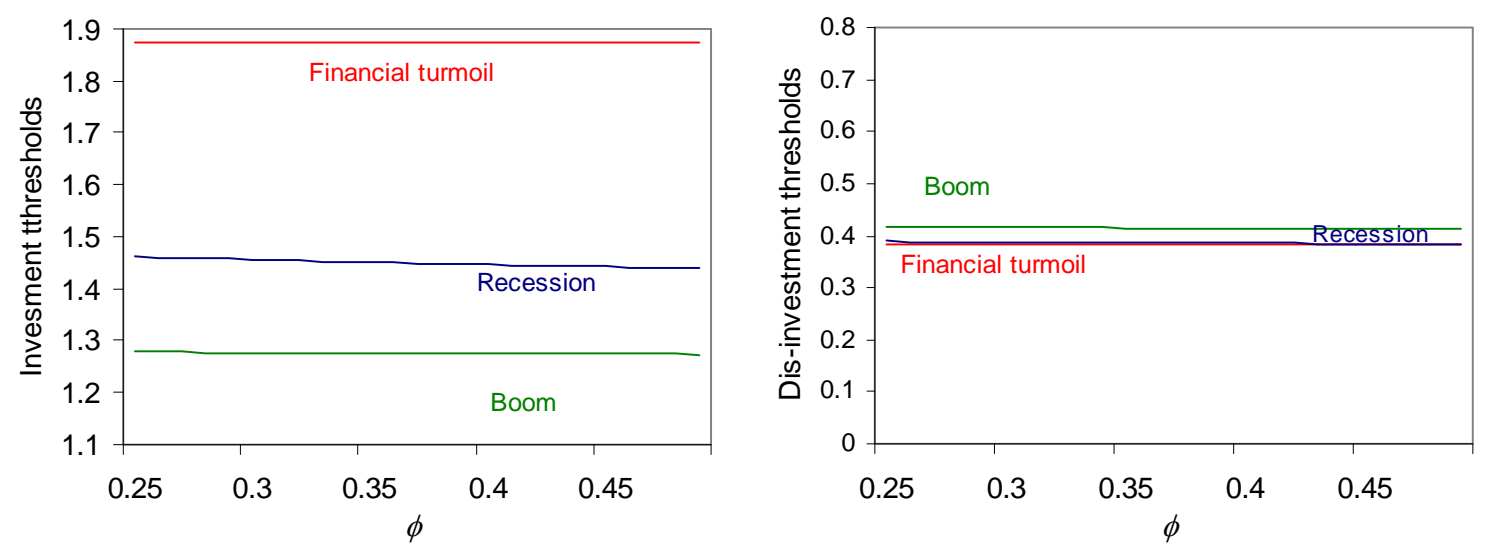

Figure 4 and 5 provide a sensitivity analysis of the thresholds with respect to $\lambda_{0}$ and $\lambda_{1}$, i.e. we illustrate the impact of varying probabilities to switch from boom to turmoil vs. boom to recession. The widening of the inaction areas indicates that higher $\lambda$ values make adjustment of the capital stock in boom periods more risky, which tends to lower firms' willingness to invest during booms accordingly.

assigning probabilities to flawed predictions is a waste of time and appears to contain more information than it usually does.

${ }^{19}$ The result that the inaction areas are relatively insensitive to the expected length of the recession and financial turmoil states coincides with the calibration results done in Hassler (1996, p. 1129). 
Figure 4: The Impact of $\lambda_{0}$ Upon the $Z$ Thresholds
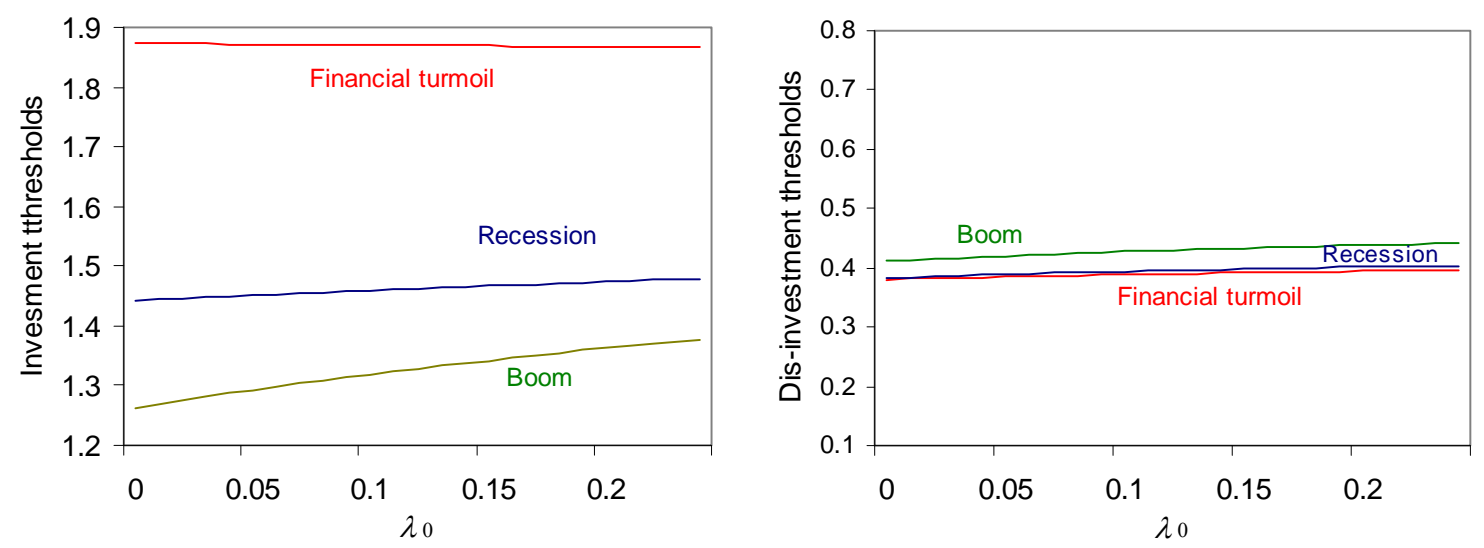

Figure 5: The Impact of $\lambda_{1}$ Upon the $Z$ Thresholds
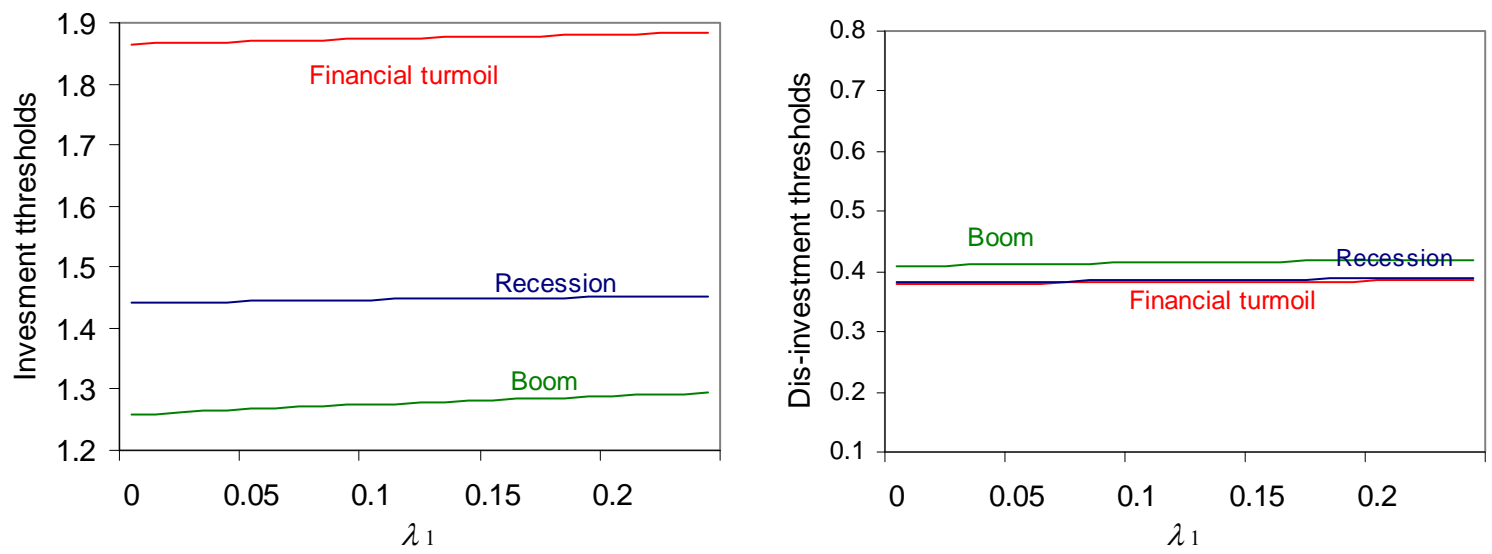

Let us now consider changes in $\sigma_{\mathrm{i}}(i=0,1,2)$. In other words, we analyse the sensitivity of the optimal thresholds with respect to changes in the volatility of the geometric Brownian motion in booms, recessions and during periods of financial turmoil. As in the existing literature, we find that the threshold value at which investment takes place is increasing in the "noisiness" level even though the firm is risk neutral. In more volatile environments, the best tactic is to keep options open and await new information rather than commit an investment today. The comparison of the left and right panels of Figures 6-8 indicates that the $\mathrm{Z}^{+}$thresholds are much more sensitive to changes in $\sigma$ than the $\mathrm{Z}^{-}$ thresholds. 
Figure 6: The Impact of $\sigma_{0}$ Upon the $Z$ Thresholds
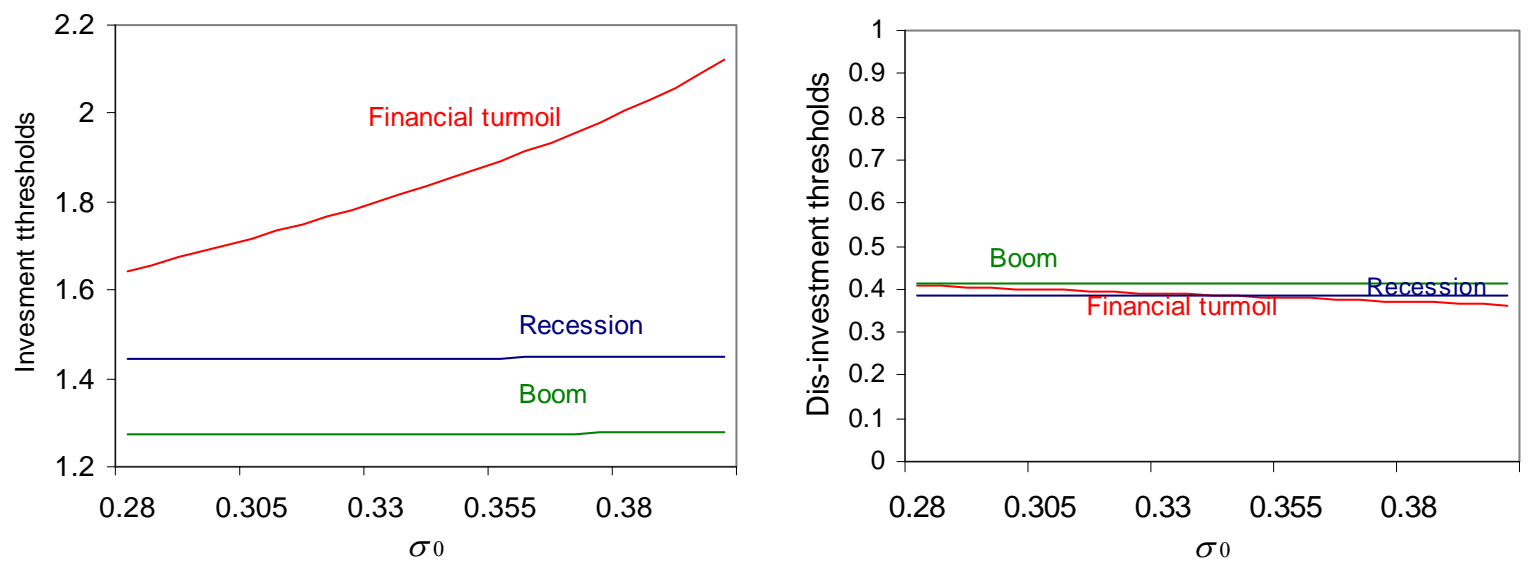

Figure 7: The Impact of $\sigma_{1}$ Upon the $Z$ Thresholds
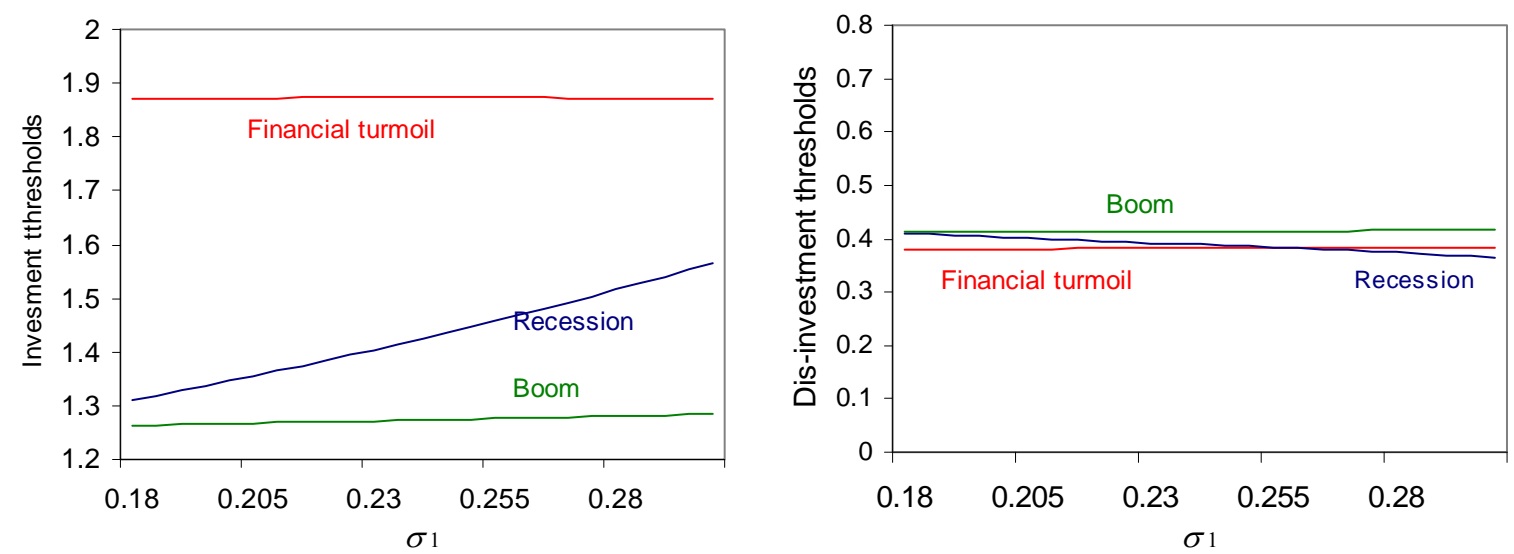

Figure 8: The Impact of $\sigma_{2}$ Upon the $Z$ Thresholds
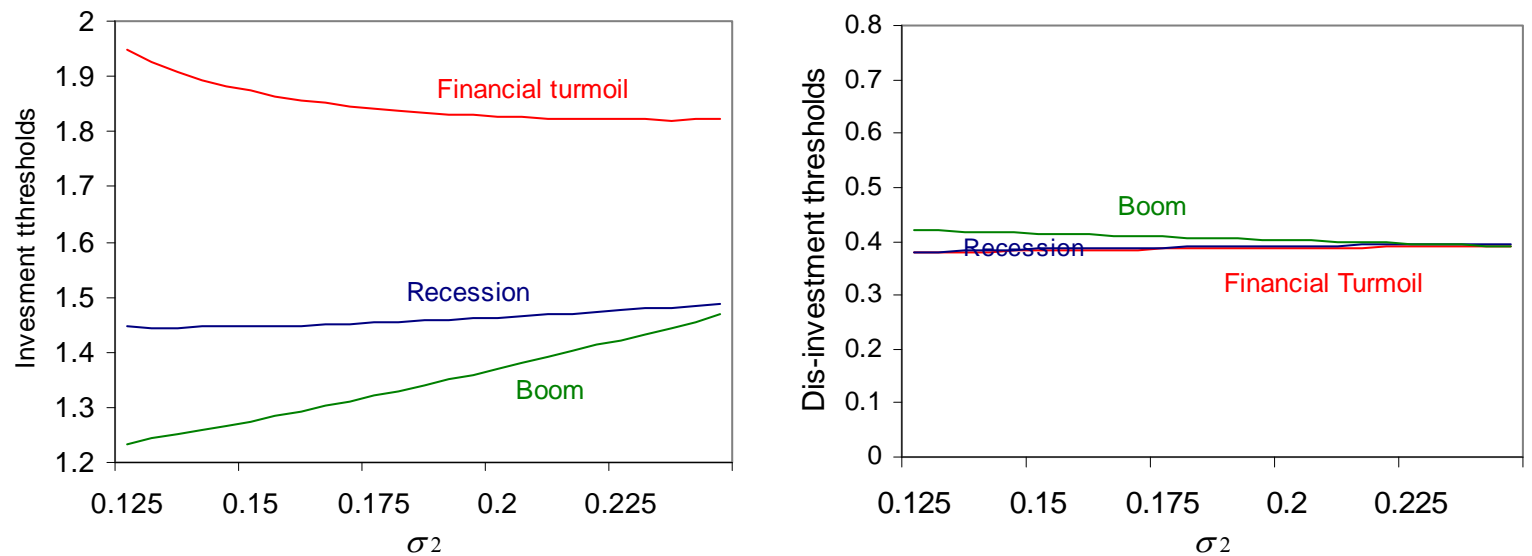

In order to shed further light on the model, we analyse how the inaction bands depends upon the mean growth rate in boom periods. While the nature of the recovery from the current financial crisis has important impacts, there is something that eventually will have a much bigger impact in the mediumand long-run than the slope of the recovery: That is the effect of the crisis on the (expected) potential 
rate of growth during boom periods. This potential growth rate is represented by the drift term $\eta_{2}$ in our model. The pace at which GDP can expand is mainly determined by the speed with which productivity improves. Will the current financial crisis make things worse? In theory, it could do. Slumping investment may slow the pace of innovation. More regulation, in finance and beyond, could further deter innovation. Workers' skills may vanish as a result of unemployment. On the contrary, however, there are reasons to believe that one may get better from bad. The crisis enforces "creative destruction" across markets and industries, simultaneously creating new products and business models. In this way, creative destruction is largely responsible for the dynamism of industries and long-run economic growth. ${ }^{20}$ The numerical results in Figure 9 have an immediate interpretation: An increasing drift term reduces the precautionary motive for waiting over and above investing.

\section{Figure 9: The Impact of $\eta_{2}$ Upon the $Z$ Thresholds}
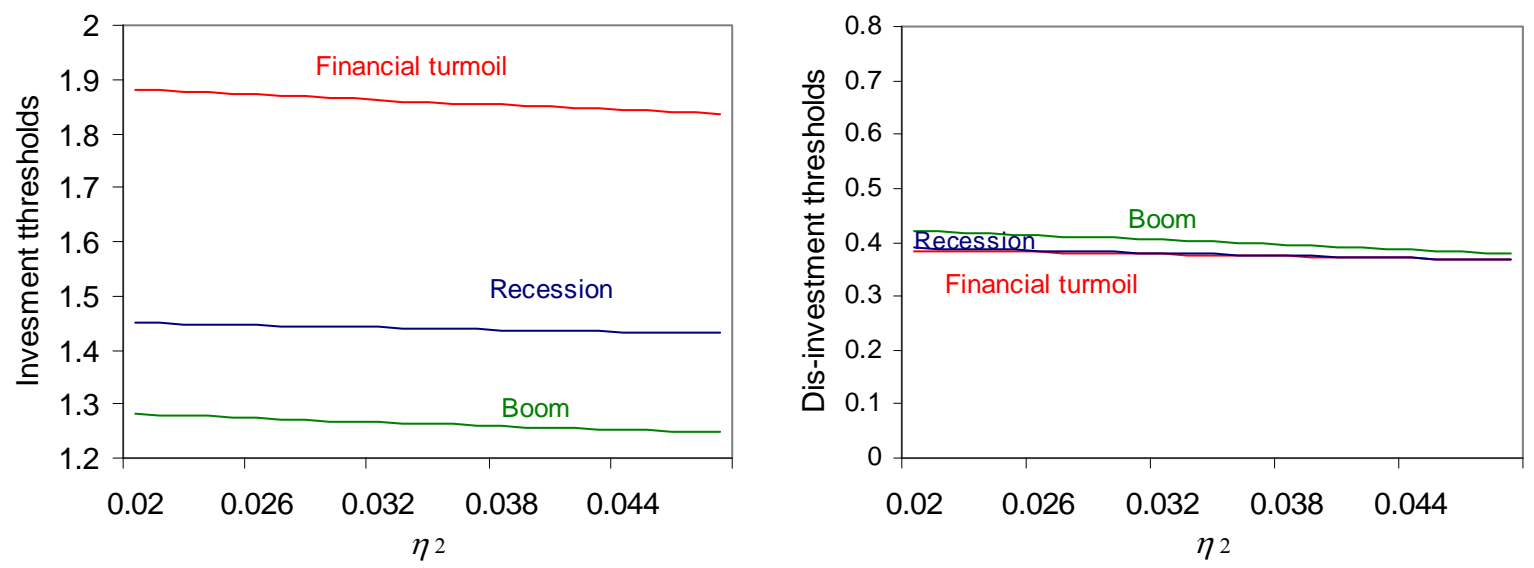

Since the focus of the paper is investment, we next present a translation from thresholds to investment and the capital stock and assess the impact of the three regimes upon investment. In other words, we "reverse engineer" time series for investment and the capital stock from our setup. In this validation stage, we also test the ability of our model to replicate some business cycle characteristics by using numerical simulations of the dynamic system.

We first have to specify a solution method that will lead us to generate discrete realizations of the endogenous variables, given the chosen levels of parameters. ${ }^{21}$ Below we specify a sequential iterations method that allows us to generate discrete realizations of the nonlinear dynamical system and investigate the oscillations, given the chosen levels of parameters. It works as follows. Equation (6) is proxied by the following discrete stochastic differential equation - the Euler scheme,

\footnotetext{
${ }^{20}$ For a comprehensive review of creative destruction growth models, see Aghion and Howitt (2009). In recent years, the Swedish experience offers grounds for optimism. Its productivity growth accelerated after the early 1990s financial crisis, in part because the government dealt swiftly with the banking mess.

${ }^{21}$ It might appear that the impact of uncertainty is always to lower investment expenditures. This is, however, not the case. The intuitive reason for this finding is that while uncertainty as measured by the variance
} 


$$
Z_{t+\Delta t}-Z_{t}=\eta_{i} Z_{t} \Delta t+\sigma_{i} \sqrt{\Delta t} Z_{t} \varepsilon_{t}, \quad \varepsilon_{t} \sim N(0,1) \quad \text { for } i=0,1,2
$$

where the normal random variables, $\varepsilon_{t}$, are generated via the central limit theorem and the Box-Muller (1985) method for transforming a uniformly distributed random variables to a normal distribution with given mean and variance. ${ }^{22}$ As the time passes, the term $Z_{t}$ fluctuates according to the corresponding stochastic processes and $K$ will depreciate as long as $Z_{t}$ is staying within the no-action area. If $Z_{t}$ hits the threshold $Z_{1}^{+}$in state 1 or the threshold $Z_{0}^{+}$in state 0 , the firm will invest according to

$$
I_{t}=\frac{q_{i}\left(Z_{t}\right)-p_{K}^{+}}{\gamma}=\frac{q_{i}\left(Z_{t}\right)-q_{1}\left(Z_{1}^{+}\right)}{\gamma} \quad \text { for } i=0,1,2
$$

We use the differences between the particular solutions to proxy the value of $q_{i}\left(Z_{t}\right)-q_{i}\left(Z_{1}^{+}\right)$. The same approach is applied to the calculation of dis-investment. After the level of investment is determined, the corresponding capital stock is computed using the capital accumulation constraint

$$
K_{t+1}=K_{t}+I_{t}-\delta K_{t}
$$

which become the initial value of $K$ for the time $t+1$, by which the new thresholds are recomputed accordingly for the time $t+1$. With the aid of this numerical solution principle, the adjustment paths can be simulated. What do these dynamic adjustment paths look like? One sample path of the stochastic adjustment process is given in Figure 10. Superimposed on the graphs are the (stochastic) booms, recession, and financial turmoil phases. ${ }^{23}$ The financial turmoil period occurs once over the sample period and lasts for three years.

The Figure visualizes three (alternative) realizations of the demand shock $Z$, the four threshold variables, the sequence of expansions versus recessions (indicated by the broken vertical lines) and the corresponding optimal net investment and installed capital stock time series over 30 years. We immediately see that net investment always occurs when the firm "by accident" hits the relevant

parameters raises the threshold level for investment to occur (negative first-order effect), it also raises volatility, allowing $Z$ to hit the thresholds more often (positive second-order effect).

${ }^{22}$ See, for example, Press et al. (1992) for a description of the algorithm. The initial value for $Z_{t=0}$ is $0.65, \Delta t=$ 0.2 and $\gamma=1.0$. All other parameters are as in the benchmark case.

${ }^{23}$ It should be pointed out that Figure 10 display the results for one seed for the random number generator, and might not represent a typical or average path. 
threshold. ${ }^{24}$ Furthermore, the sample paths" of $I$ and $K$ are "zigzagging”, i.e. the overall finding is that the Markov-switching framework can indeed mimic actual cyclical movements in $I$ and $K .^{25}$

Up to now, we have interpreted the model as applying to a single firm. Suppose that we re-interpret the model at the macroeconomic level, i.e. $K$ and $I$ now represent economy-wide gross investment and the capital stock, respectively, and the interpretation of $q$ is likewise altered. Unlike microeconomic data, aggregate investment series look smoother since microeconomic adjustments are far from being perfectly synchronized. The question arises as to whether aggregation eliminates all traces of infrequent lumpy microeconomic adjustment. We again focus on investment $(I)$, and we model aggregate investment in terms of average investment of a large number of individual firms indexed by $i \in[1,2000] .{ }^{26}$ This is close to a controlled laboratory experiment. Experimentation with larger numbers of runs shows no significant change to the results. For the sake of simplicity, we initially assume that the business cycles turning points are perfectly correlated across firms, i.e. all firms are "dancing in steps". The resulting dynamics of investment (I) resulting from the 2000 stochastic sample paths is given in Figure 12 for $\gamma=1,2$ and 4, respectively. As expected, higher adjustment costs (larger $\gamma$ ) lead to a smoother business cycle. On the other hand, investment $(I)$ is still rather "zigzagging”.

\footnotetext{
${ }^{24}$ In the simulations, the firm never hits the disinvestment threshold given the resale price $p_{K}{ }^{-}=0.4$. Therefore, disinvestment never takes place although it is physically possible.

${ }^{25}$ Investment at the firm level is characterised by major and infrequent adjustments. Cooper et al. (1999), for example, have documented this lumpiness.

${ }^{26}$ We have ignored behavioural assumptions regarding market rivalry, which in turn would necessitate some kind of game-theoretic analysis to take account of the strategic interactions among the firms, results of which are in turn heavily dependent on assumptions regarding the information sets available and the type of game being played. Leahy (1993) has shown that the assumption of myopic firms who ignore the impact of other firms' actions results in the same critical boundaries that trigger investment as a model in which firms correctly anticipate the strategies of other firms. Grenadier (2002) has recently extended Leahy's (1993) "Principle of Optimality of Myopic Behavior" to the apparently more complex case of dynamic oligopoly under uncertainty. Both papers therefore permit to bypass strategic general equilibrium considerations when analysing factor demand under uncertainty.
} 
Figure 10: A Sample Path of the Demand Shock (Z), the Z-Thresholds, Installed Capital (K), and Optimal Investment
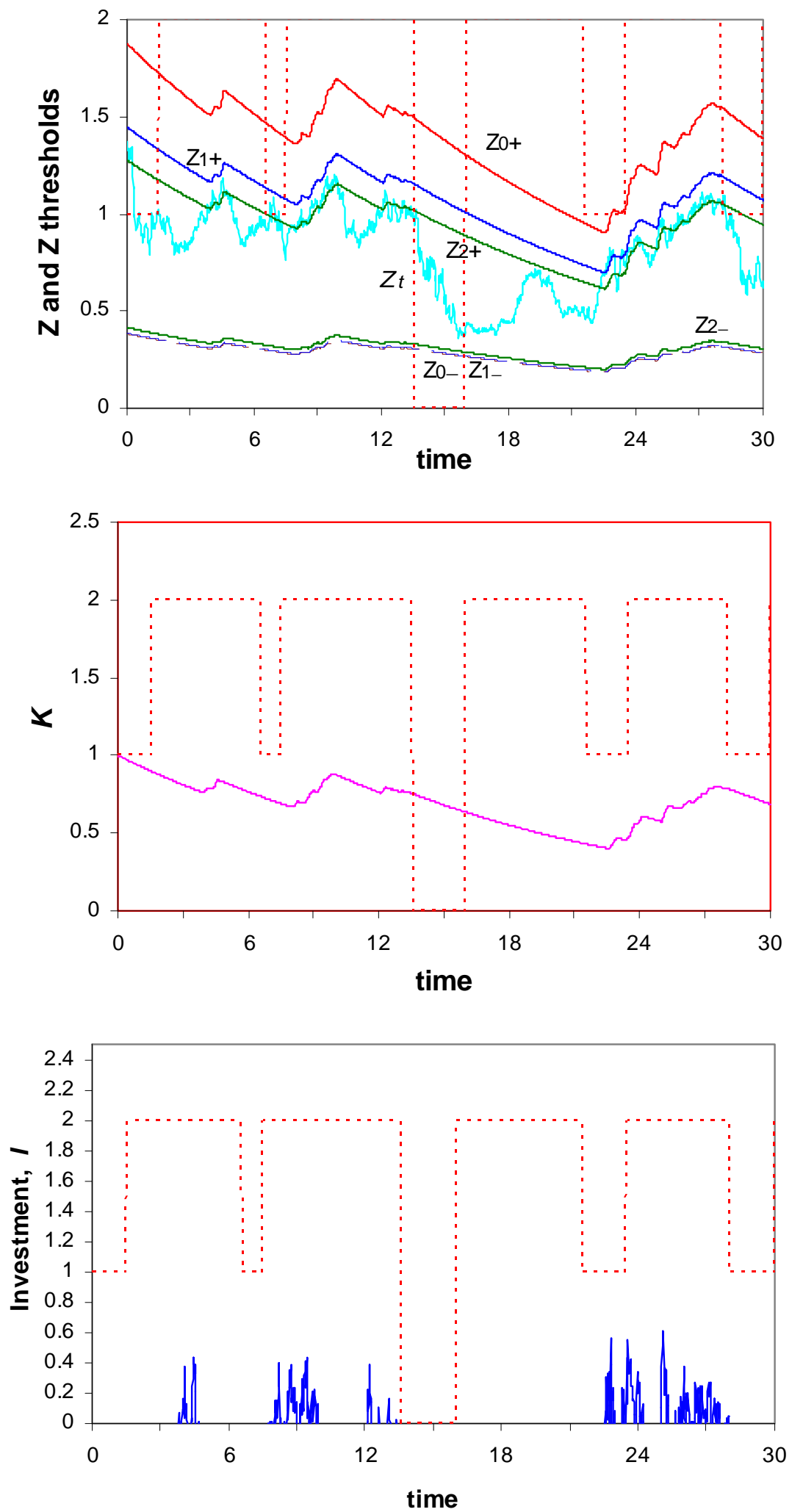
Figure 11: Aggregate Dynamics for Perfectly Synchronised Business Cycle Turning Points

(a) Investment Dynamics for $\gamma=1$

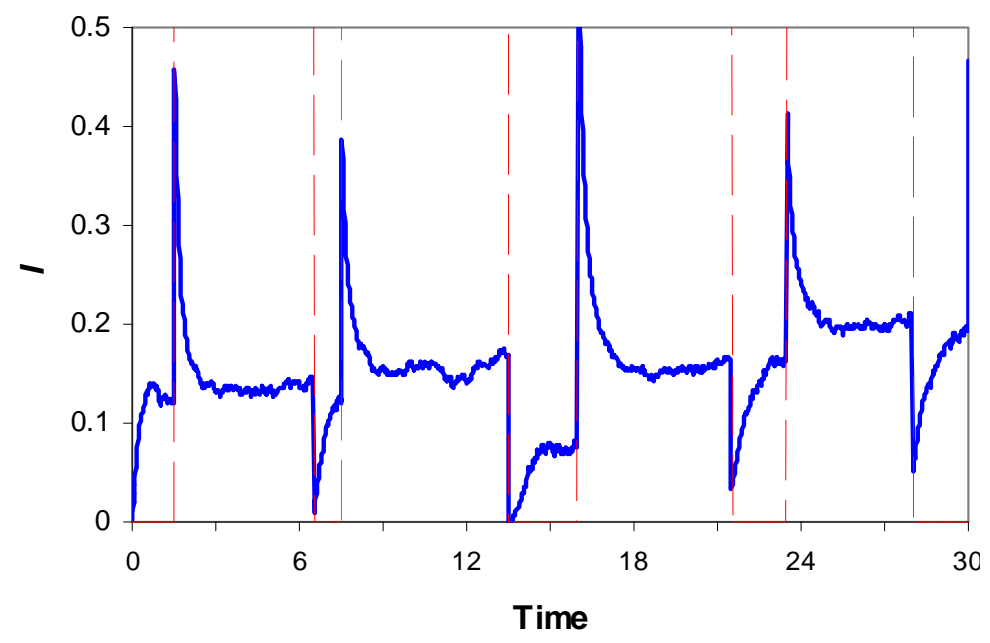

(b) Investment Dynamics for $\gamma=2$

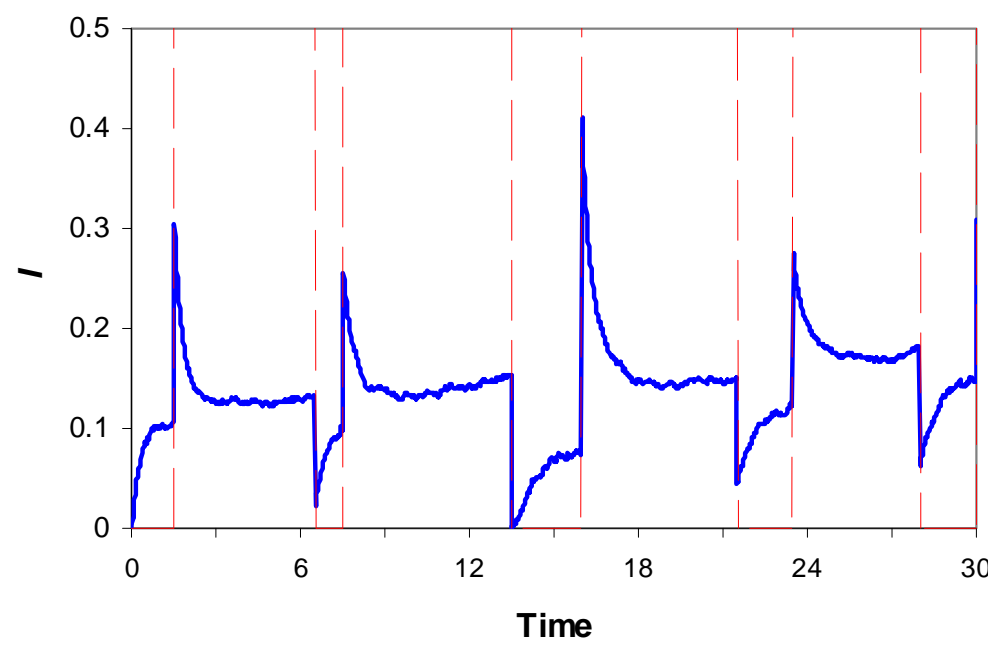

(c) Investment Dynamics for $\gamma=4$

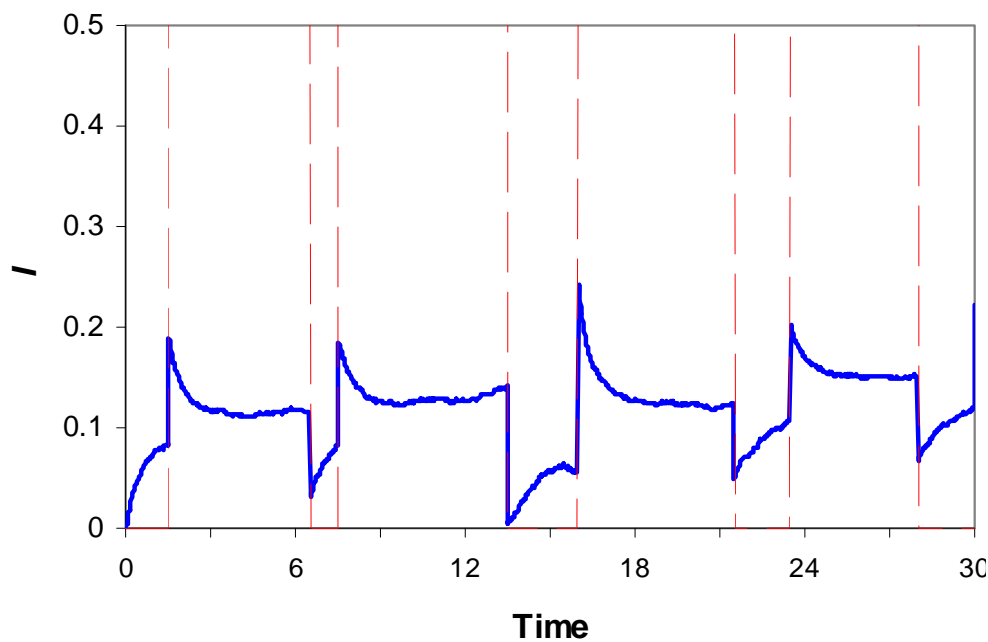


Figure 12: Aggregate Dynamics for Heterogeneous Business Cycles Turning Points (a) Investment Dynamics for $\gamma=1$ and $N(0,0.00)$ around state-switching points

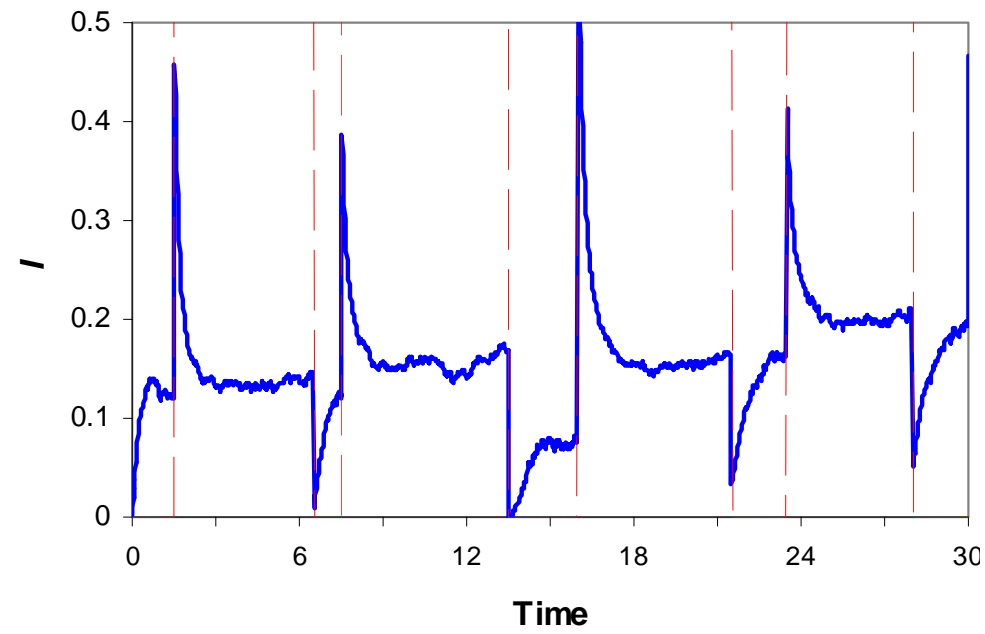

(b) Investment Dynamics for $\gamma=1$ and $N(0,0.05)$ around state-switching points

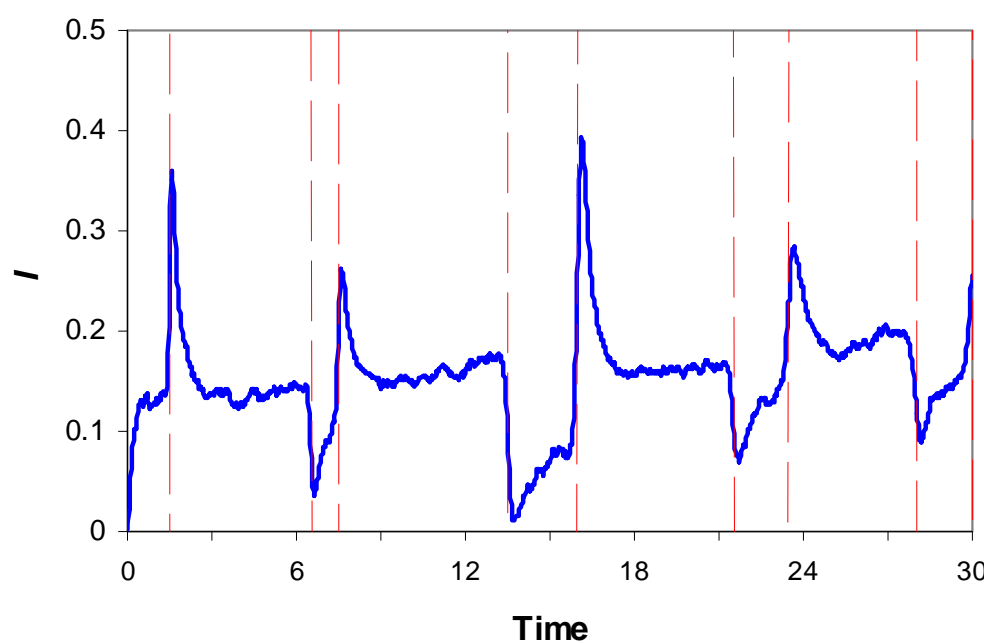

(c) Investment Dynamics for $\gamma=1$ and $N(0,0.1)$ around state-switching points

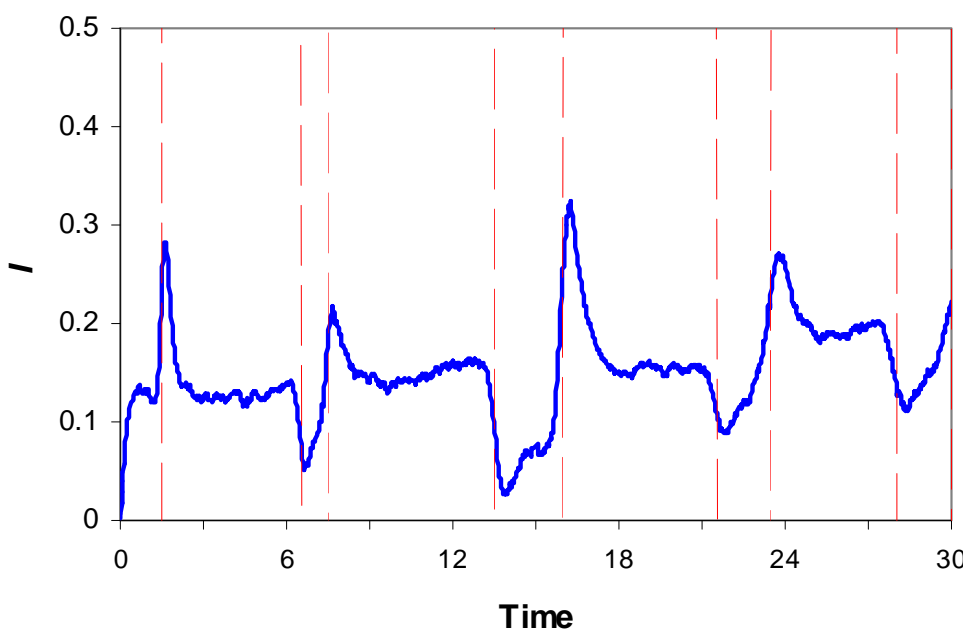


In order to accommodate further differentiation among firms, we finally employ a "hybrid" model that endogenises the business cycle turning points. Suppose that at each turning point, the proportion of firms experiencing a peak (trough) at time $t$ is assumed to be drawn at random from a standard normal distribution around the predefined turning points in Figure 10. In an economic context, this choice of a nomal distribution has no clear theoretical underpinning, but is motivated by the desire to build a version of the model that can reasonably mimic heterogeneous turning points. Figure 12 shows the results of this exercise graphically. Qualitatively, the results for the three scenarios are intuitive since as the dispersion of business cycle turning points increases, the sharpness of the turning points of the aggregate business cycle declines. ${ }^{27}$ Although the individual sample paths are far from being synchronised because of idiosyncratic Z-shocks, the hybrid model nevertheless converges to more gradual business cycles. Thus, our analysis provides an example of the insights to be gained by combining microeconomic modelling of heterogeneous firms with macroeconomic issues. The Markov-switching specification can indeed mimic actual cyclical movements in $I$ and $K{ }^{28}$

\section{Summary and Conclusions}

The paper has covered a lot of ground. Let us repeat some key ideas and develop some of the earlier conclusions. The focus of this article has been the incorporation of jump dynamics into real options models in order to improve understanding of cyclical investment behaviour, especially in the most volatile era. The paper strives to provide a unifying framework that makes explicit and clarifies thinking on the inter-linkages between cyclical uncertainty, option value and the choice and timing of investment. With the aim of parsimony in mind, but also wanting to ensure a fair degree of reality, we extend and generalize a standard model of irreversible investment by introducing a three-state Markov-switching model. The Markov-switching modelling approach allows the derivation of analytical and numerical results on option pricing, taking into account that firms not only either observe or infer the current state of the system but also make predictions about future regime switches. The chief implication of the model is that recessions and financial turmoil periods are important catalysts for waiting. Clearly, this sort of analysis is only a first step. Nevertheless, the model provides a useful template of how to approach the task and it may lead to an enriched understanding of the dynamics of investment during the business cycle.

\footnotetext{
${ }^{27}$ The simulations of this section are meant only to be illustrative. One may argue that a constant variance (standard deviation) is inappropriate because in recent years business cycle turning points have become more correlated (for example, due to the boom and bust in information-technology shares). Nevertheless, we believe that they demonstrate the potential of our modelling framework to clarify the implications of cyclical uncertainty.

${ }^{28}$ Investment at the firm level is characterized by major and infrequent adjustments. Cooper et al. (1999), for example, have documented this lumpiness.
} 


\section{Appendix: The Particular and Homogenous Solutions for $q$}

Substituting $\left(I=q_{i}-p_{K}^{+-} / \gamma\right)$ from equation (12) in the text back into the Bellman equations (9)-(11) respectively yields

$$
\begin{aligned}
r V_{0}= & Z K^{\alpha_{1}} N^{\alpha_{2}}-x K-w N+\frac{\left(q_{0}-p_{K}^{+--}\right)^{2}}{2 \gamma}-\delta q_{0} K+\eta_{0} Z V_{0 Z}+\frac{1}{2} \sigma_{0}^{2} Z^{2} V_{0 Z Z}+\theta\left(V_{2}-V_{0}\right) \\
r V_{1}= & Z K^{\alpha_{1}} N^{\alpha_{2}}-x K-w N+\frac{\left(q_{1}-p_{K}^{+/-}\right)^{2}}{2 \gamma}-\delta q_{1} K+\eta_{1} Z V_{1 Z}+\frac{1}{2} \sigma_{1}^{2} Z^{2} V_{1 Z Z}+\phi\left(V_{2}-V_{1}\right) \\
r V_{2}= & Z K^{\alpha_{1}} N^{\alpha_{2}}-x K-w N+\frac{\left(q_{2}-p_{K}^{+/-}\right)^{2}}{2 \gamma}-\delta q_{2} K+\eta_{2} Z V_{2 Z}+\frac{1}{2} \sigma_{2}^{2} Z^{2} V_{2 Z Z} \\
& +\lambda_{0}\left(V_{0}-V_{2}\right)+\lambda_{1}\left(V_{1}-V_{2}\right) .
\end{aligned}
$$

Using the definitions $q_{i}=V_{i K}, q_{i Z}=V_{i K Z}, q_{i K}=V_{i K K}$ and $q_{i Z Z}=V_{i K Z Z}$ for $i=0,1,2$ and differentiating both sides of equations (A1) - (A3) with respect to $K$ yields

$$
\begin{aligned}
(r+\delta) q_{0}= & \alpha_{1} Z K^{\alpha_{1}-1} N^{\alpha_{2}}-x+\frac{\left(q_{0}-p_{K}^{+/-}\right) q_{0 K}}{\gamma}-\delta q_{0 K} K+\eta_{0} Z q_{0 Z}+\frac{1}{2} \sigma_{0}^{2} Z^{2} q_{0 Z Z}+\theta\left(q_{2}-q_{0}\right) \\
(r+\delta) q_{1}= & \alpha_{1} Z K^{\alpha_{1}-1} N^{\alpha_{2}}-x+\frac{\left(q_{1}-p_{K}^{+-}\right) q_{1 K}}{\gamma}-\delta q_{1 K} K+\eta_{1} Z q_{1 Z}+\frac{1}{2} \sigma_{1}^{2} Z^{2} q_{1 Z Z}+\phi\left(q_{2}-q_{1}\right) \\
(r+\delta) q_{2}= & \alpha_{1} Z K^{\alpha_{1}-1} N^{\alpha_{2}}-x+\frac{\left(q_{2}-p_{K}^{+/-}\right) q_{2 K}}{\gamma}-\delta q_{2 K} K+\eta_{2} Z q_{2 Z}+\frac{1}{2} \sigma_{2}^{2} Z^{2} q_{2 Z Z} \\
& +\lambda_{0}\left(q_{0}-q_{2}\right)+\lambda_{1}\left(q_{1}-q_{2}\right)
\end{aligned}
$$

The terms of $\left(q_{0}-p_{K}^{+-}\right) q_{0 K} / \gamma$ and $\left(q_{1}-p_{K}^{+--}\right) q_{1 K} / \gamma,\left(q_{2}-p_{K}^{+-}\right) q_{2 K} / \gamma$ lead to some difficulty in solving the partial differential equations of equations (A4) - (A6). When $q=p_{K}^{+}$or $q=p_{K}^{-}$, the firm just begins to invest or disinvest $(I=0)$, so that equations (A4) - (A6) becomes solvable analytically and the parameter $\gamma$ has no impact on the thresholds. For the out-of-zone investment $\left(q>p_{K}^{+}\right)$or disinvestment $\left(q<p_{K}^{-}\right)$, the parameter $\gamma$ does affect the optimal capital decisions of the firm but there is no closed form solution in this case. When solving for the inaction regions, equations (A4) - (A6) takes the following simpler forms:

$$
\begin{aligned}
& (r+\delta) q_{0}=\alpha_{1} Z K^{\alpha_{1}-1} N^{\alpha_{2}}-x-\delta q_{0 K} K+\eta_{0} Z q_{0 Z}+\frac{1}{2} \sigma_{0}^{2} Z^{2} q_{0 Z Z}+\theta\left(q_{2}-q_{0}\right) \\
& (r+\delta) q_{1}=\alpha_{1} Z K^{\alpha_{1}-1} N^{\alpha_{2}}-x-\delta q_{1 K} K+\eta_{1} Z q_{1 Z}+\frac{1}{2} \sigma_{1}^{2} Z^{2} q_{1 Z Z}+\phi\left(q_{2}-q_{1}\right) \\
& (r+\delta) q_{2}=\alpha_{1} Z K^{\alpha_{1}-1} N^{\alpha_{2}}-x-\delta q_{2 K} K+\eta_{2} Z q_{2 Z}+\frac{1}{2} \sigma_{2}^{2} Z^{2} q_{2 Z Z}+\lambda_{0}\left(q_{0}-q_{2}\right)+\lambda_{1}\left(q_{1}-q_{2}\right)
\end{aligned}
$$

The coupling of equations (A7) - (A9) leads to a six-threshold system that needs to be solved simultaneously. The solutions for $q_{0}$ and $q_{1}$ both consist of particular solutions and general solutions so that $q_{0}=q_{0}^{P}+q_{0}^{G}, q_{1}=q_{1}^{P}+q_{1}^{G}$, and $q_{2}=q_{2}^{P}+q_{2}^{G}$. The particular solutions follow from the following equations: 
(A10) $q_{0}^{P}=a_{0} Z K^{\alpha_{1}-1} N^{\alpha_{2}}+c_{0}$,

(A11) $q_{1}^{P}=a_{1} Z K^{\alpha_{1}-1} N^{\alpha_{2}}+c_{1}$,

(A12) $q_{2}^{P}=a_{3} Z K^{\alpha_{1}-1} N^{\alpha_{2}}+c_{2}$,

Plugging into equations (A7) - (A9), we get

(A13) $\left[a_{0}\left(r+\delta+\delta\left(\alpha_{1}-1\right)-\eta_{0}+\theta\right)-\theta a_{2}-\alpha_{1}\right] a_{0} Z K^{\alpha_{1}-1} N^{\alpha_{2}}+\left[c_{0}(r+\delta+\theta)-\theta c_{2}+x\right]=0$

(A14) $\left[a_{1}\left(r+\delta+\delta\left(\alpha_{1}-1\right)-\eta_{1}+\phi\right)-\phi a_{2}-\alpha_{1}\right] a_{0} Z K^{\alpha_{1}-1} N^{\alpha_{2}}+\left[c_{1}(r+\delta+\phi)-\phi c_{2}+k\right]=0$.

(A15) $\left[-\lambda_{0} a_{0}-\lambda_{1} a_{1}+a_{2}\left(r+\delta+\delta\left(\alpha_{1}-1\right)-\eta_{2}+\lambda_{0}+\lambda_{1}\right)-\alpha_{1}\right] a_{0} Z K^{\alpha_{1}-1} N^{\alpha_{2}}$. $+\left[-\lambda_{0} c_{0}-\lambda_{1} c_{1}+c_{2}\left(r+\delta+\lambda_{0}+\lambda_{1}\right)+x\right]=0$

Equations (A13) - (A15) hold if all items in brackets are set to zero. Therefore, we have the following three equations for $a_{0}, a_{1}$, and $a_{2}$

(A16) $a_{0}\left(r+\delta+\delta\left(\alpha_{1}-1\right)-\eta_{0}+\theta\right)-\theta a_{2}-\alpha_{1}=0$,

(A17) $a_{1}\left(r+\delta+\delta\left(\alpha_{1}-1\right)-\eta_{1}+\phi\right)-\phi a_{2}-\alpha_{1}=0$,

(A18) $-\lambda_{0} a_{0}-\lambda_{1} a_{1}+a_{2}\left(r+\delta+\delta\left(\alpha_{1}-1\right)-\eta_{2}+\lambda_{0}+\lambda_{1}\right)-\alpha_{1}$;

and we have the following three equations for $c_{0}, c_{1}$, and $c_{2}$

(A19) $c_{0}(r+\delta+\theta)+0-\theta c_{2}=-x$

(A20) $0+c_{1}(r+\delta+\phi)-\phi c_{2}=-x$.

(A21) $-\lambda_{0} c_{0}-\lambda_{1} c_{1}+a_{2}\left(r+\delta+\lambda_{0}+\lambda_{1}\right)=-x$;

Therefore, by Cramer's rule it follows directly that

(A19) $a_{0}=\frac{\alpha_{1}\left(b_{1} b_{2}+\alpha_{1} \lambda_{1} \theta+\theta b_{1}-\lambda_{1} \phi\right)}{b_{0} b_{1} b_{2}-\lambda_{0} \theta b_{1}-\lambda_{1} \phi b_{0}}$,

(A20) $a_{1}=\frac{\alpha_{1}\left(b_{0} b_{2}+\lambda_{0} \phi+\phi b_{0}-\lambda_{0} \theta\right)}{b_{0} b_{1} b_{2}-\lambda_{0} \theta b_{1}-\lambda_{1} \phi b_{0}}$

(A21) $a_{2}=\frac{\alpha_{1}\left(b_{0} b_{1}+\lambda_{0} b_{1}+\lambda_{1} b_{0}\right)}{b_{0} b_{1} b_{2}-\lambda_{0} \theta b_{1}-\lambda_{1} \phi b_{0}}$

(A22) $c_{0}=-\frac{x\left(d_{1} d_{2}+\lambda_{1} \theta+\theta d_{1}-\lambda_{1} \phi\right)}{d_{0} d_{1} d_{2}-\lambda_{0} \theta d_{1}-\lambda_{1} \phi d_{0}}$,

(A23) $c_{1}=-\frac{x\left(d_{0} d_{2}+\lambda_{0} \phi+\phi d_{0}-\lambda_{0} \theta\right)}{d_{0} d_{1} d_{2}-\lambda_{0} \theta d_{1}-\lambda_{1} \phi d_{0}}$,

(A24) $c_{2}=-\frac{x\left(d_{0} d_{1}+\lambda_{0} d_{1}+\lambda_{1} d_{0}\right)}{d_{0} d_{1} d_{2}-\lambda_{0} \theta d_{1}-\lambda_{1} \phi d_{0}}$,

where

(A25) $b_{0}=r+\delta+\delta\left(\alpha_{1}-1\right)-\eta_{0}+\theta$,

(A26) $b_{1}=r+\delta+\delta\left(\alpha_{1}-1\right)-\eta_{1}+\phi$,

(A27) $b_{2}=r+\delta+\delta\left(\alpha_{1}-1\right)-\eta_{2}+\lambda_{0}+\lambda_{1}$, 
(A28) $d_{0}=r+\delta+\theta$,

(A29) $d_{1}=r+\delta+\phi$,

(A30) $d_{2}=r+\delta+\lambda_{0}+\lambda_{1}$.

It is straightforward to see that $c=c_{0}=c_{1}=c_{2}$. Thus, $c=x /(r+\delta)$. The homogenous parts of equations (A7) - (A9) are represented by the following:

(A31) $(r+\delta) q_{0}=-\delta q_{0 K} K+\eta_{0} Z q_{0 Z}+\frac{1}{2} \sigma_{0}^{2} Z^{2} q_{0 Z Z}+\theta\left(q_{2}-q_{0}\right)$

(A32) $(r+\delta) q_{1}=-\delta q_{1 K} K+\eta_{1} Z q_{1 Z}+\frac{1}{2} \sigma_{1}^{2} Z^{2} q_{1 Z Z}+\phi\left(q_{2}-q_{1}\right)$.

(A33) $(r+\delta) q_{2}=-\delta q_{2 K} K+\eta_{2} Z q_{2 Z}+\frac{1}{2} \sigma_{2}^{2} Z^{2} q_{2 Z Z}+\lambda_{0}\left(q_{0}-q_{2}\right)+\lambda_{1}\left(q_{1}-q_{2}\right)$.

The problem is simplified by observing that $N$ is constant. Let us therefore assume that the general solutions have the following functional forms:

(A34) $q_{0}^{G}=A\left(Z K^{\alpha_{1}-1}\right)^{\beta}$

(A35) $q_{1}^{G}=B\left(Z K^{\alpha_{1}-1}\right)^{\beta}$.

(A36) $q_{2}^{G}=C\left(Z K^{\alpha_{1}-1}\right)^{\beta}$.

Substituting (A34) - (A36) into (A31) - (A33) yields

$$
\begin{aligned}
& A\left(r+\delta+\delta \beta\left(\alpha_{1}-1\right)-\eta_{0} \beta-\frac{1}{2} \sigma_{0}^{2} \beta(\beta-1)+\theta\right)=C \theta \\
& B\left(r+\delta+\delta \beta\left(\alpha_{1}-1\right)-\eta_{1} \beta-\frac{1}{2} \sigma_{1}^{2} \beta(\beta-1)+\phi\right)=C \phi \\
& C\left(r+\delta+\delta \beta\left(\alpha_{1}-1\right)-\eta_{2} \beta-\frac{1}{2} \sigma_{2}^{2} \beta(\beta-1)+\lambda_{0}+\lambda_{1}\right)=A \lambda_{0}+B \lambda_{1}
\end{aligned}
$$

To obtain the characteristic equation for betas, we need to substitute (A37) and (A38) into (A39). Rearranging yields:

$$
\begin{aligned}
& \left(r+\delta+\delta \beta\left(\alpha_{1}-1\right)-\eta_{2} \beta-\frac{1}{2} \sigma_{2}^{2} \beta(\beta-1)+\lambda_{0}+\lambda_{1}\right) \times\left(r+\delta+\delta \beta\left(\alpha_{1}-1\right)-\eta_{0} \beta-\frac{1}{2} \sigma_{0}^{2} \beta(\beta-1)+\theta\right) \\
& \times\left(r+\delta+\delta \beta\left(\alpha_{1}-1\right)-\eta_{1} \beta-\frac{1}{2} \sigma_{1}^{2} \beta(\beta-1)+\phi\right)=\theta \lambda_{0}\left(r+\delta+\delta \beta\left(\alpha_{1}-1\right)-\eta_{1} \beta-\frac{1}{2} \sigma_{1}^{2} \beta(\beta-1)+\phi\right) . \\
& +\phi \lambda_{1}\left(r+\delta+\delta \beta\left(\alpha_{1}-1\right)-\eta_{0} \beta-\frac{1}{2} \sigma_{0}^{2} \beta(\beta-1)+\theta\right) .
\end{aligned}
$$

It is obvious that there are six roots for the above characteristic equations: three postive $\left(\beta_{1}, \beta_{2}, \beta_{3}\right)$ and three negative $\left(\beta_{4}, \beta_{5}, \beta_{6}\right)$. Thus, the homogenous solutions become

(A41) $q_{0}^{G}=-A_{1}\left(Z K^{\alpha_{1}-1}\right)^{\beta_{1}}-A_{2}\left(Z K^{\alpha_{1}-1}\right)^{\beta_{2}}-A_{3}\left(Z K^{\alpha_{1}-1}\right)^{\beta_{3}}+A_{4}\left(Z K^{\alpha_{1}-1}\right)^{\beta_{4}}+A_{5}\left(Z K^{\alpha_{1}-1}\right)^{\beta_{5}}+A_{6}\left(Z K^{\alpha_{1}-1}\right)^{\beta_{6}}$
(A42) $q_{1}^{G}=-B_{1}\left(Z K^{\alpha_{1}-1}\right)^{\beta_{1}}-B_{2}\left(Z K^{\alpha_{1}-1}\right)^{\beta_{2}}-B_{3}\left(Z K^{\alpha_{1}-1}\right)^{\beta_{3}}+B_{4}\left(Z K^{\alpha_{1}-1}\right)^{\beta_{4}}+B_{5}\left(Z K^{\alpha_{1}-1}\right)^{\beta_{5}}+B_{6}\left(Z K^{\alpha_{1}-1}\right)^{\beta_{6}}$ 
(A43) $q_{2}^{G}=-C_{1}\left(Z K^{\alpha_{1}-1}\right)^{\beta_{1}}-C_{2}\left(Z K^{\alpha_{1}-1}\right)^{\beta_{2}}-C_{3}\left(Z K^{\alpha_{1}-1}\right)^{\beta_{3}}+C_{4}\left(Z K^{\alpha_{1}-1}\right)^{\beta_{4}}+C_{5}\left(Z K^{\alpha_{1}-1}\right)^{\beta_{5}}+C_{6}\left(Z K^{\alpha_{1}-1}\right)^{\beta_{6}}$

And we assign the following order for the characteristic roots, $\beta_{1}>\beta_{2}>\beta_{3}>0>\beta_{4}>\beta_{5}>\beta_{6}$. Note that the coefficients $A_{i}, B_{i}$, and $C_{i}$ are coupled according to equations (A37) - (A39). We arbitrarily choose (A37) and (A38)

(A44) $A_{i} \frac{\left(r+\delta+\delta \beta\left(\alpha_{1}-1\right)-\eta_{0} \beta-\frac{1}{2} \sigma_{0}^{2} \beta(\beta-1)+\theta\right)}{\theta}=C_{i}, i=1,, 6$,

(A45) $B_{i} \frac{\left(r+\delta+\delta \beta\left(\alpha_{1}-1\right)-\eta_{1} \beta-\frac{1}{2} \sigma_{1}^{2} \beta(\beta-1)+\phi\right)}{\phi}=C_{i}, i=1,,, 6$, 


\section{References:}

Abel, A.B. and J.C. Eberly (1994) “A Unified Model of Investment Under Uncertainty”, American Economic Review 84, 1369-1384.

Aghion, P. and P. Howitt (2009) The Economics of Growth, Cambridge (MIT Press).

Bagliano, F.-C. and G. Bertola (2004) Models for Dynamic Macroeconomics, Oxford (Oxford University Press).

Bartelsman, E.J. and M.E. Doms (2000) "Understanding Productivity: Lessons from Longitudinal Microdata”, Journal of Economic Literature 38, 569-594.

Blanchard, O. (2009) “(Nearly ) Nothing to Fear but Fear Itself”, The Economist, 29 January 2009, p. 72.

Bovenberg, A.L., J.J. Graafland and R.A. de Mooij (1998) Tax Reform and the Dutch Labor Market: An Applied General Equlibrium Approach, CPB Netherlands Bureau for Economic Policy Analysis, Research Memorandum 143, The Hague.

Box, G.E.P. and M.E. Muller (1958) „A Note on the Generation of Random Normal Deviates, Annals Mathematical. Statistics 29, 610-611.

Caballero, R.J. and E. Engel (1993) "Heterogeneity and Output Fluctuations in a Dynamic Menu Cost Economy”, Review of Economic Studies 60, 95-119.

Caballero, R.J., Engel, E. and J. Haltiwanger (1995) „Plant-Level Adjustment and Aggregate Investment Dynamics“, Brookings Papers on Economic Activity, No. 2/1995, 1-54.

Cardarelli, R., Elekdag, S. and S. Lall (2009) “Financial Stress, Downturns, and Recoveries”, IMF Working Papers No. 09/100, Washington.

Cecchetti, S.G., Lam, P. and N.C. Mark (1990) "Mean Reversion in Equilibrium Asset Prices", American Economic Review 80, 398-418.

Chen, Y.-F. and M. Funke (2008) "Product Market Competition, Investment and EmploymentAbundant versus Job-Poor Growth: A Real Options Perspective”, European Journal of Political Economy 24, 218-238.

Cooley, T. (Ed.) Frontiers of Business Cycle Research, Princeton (Princeton University Press).

Cooper, R., Haltiwanger, J. and L. Power (1999) „Machine Replacement and the Business Cycle: Lumps and Bumps“, American Economic Review 89, 921-946.

Dixit, A. (1989) “Entry and Exit Decisions Under Uncertainty”, Journal of Political Economy 97, 620638.

Dixit, A. and R.S. Pindyck (1994) Investment Under Uncertainty, Princeton (Princeton University Press).

Driffill, J., Raybaudi, M. and M. Sola (2003) "Investment Under Uncertainty with Stochastically Switching Profit Streams: Entry and Exit over the Business Cycle.", Studies in Nonlinear Dynamics \& Econometrics: Vol. 7: No. 1, Article 1 (http://www.bepress.com/snde/vol7/iss1/art1). 
Dunne, T., Roberts, M. and L. Samuelson (1988) "Patterns of Firm Entry and Exit in U.S. Manufacturing Industries”, Rand Journal of Economics 19, 495-515.

Engel, C. and J.D. Hamilton (1990) "Long Swings in the Dollar: Are They in the Data and Do the Markets Know it?”, American Economic Review 80, 689-713.

Ferrara, L. (2003) “A Three-Regime Real-Time Indicator for the US Economy”, Economics Letters 81, 373-378.

Grenadier, S.R. (2002) "Option Exercise Games: An Application to the Equilibrium Investment Strategies of Firms”, Review of Financial Studies 15, 691-721.

Guo, X., Miao, J. and E. Morellec (2005) "Irreversible Investment with Regime Shifts", Journal of Economic Theory 122, 37-59.

Haltiwanger, J. (2000) "Aggregate Growth: What Have We Learned From Microeconomic Evidence?”, OECD Economics Department Working Paper No. 267, Paris.

Hamilton, J.D. (1988) "Rational Expectations Econometric Analysis of changes in Regime: An Investigation of the Term Structure of Interest Rates”, Journal of Economic Dynamics and Control 12, 385-423.

Hamilton, J.D. (1989) “A New Approach to the Economic Analysis of Nonstationary Time Series and the Business Cycle”, Econometrica 57, 357-384.

Hamilton, J.D. (1990) “Analysis of Time Series Subject to Changes in Regime”, Journal of Econometrics 45, 39-70.

Hassler, J.A.A. (1996) "Variations in Risk and Fluctuations in Demand: A Theoretical Model", Journal of Economic Dynamics and Control 20, 1115-1143.

International Monetary Fund (2008) World Economic Outlook, October 2008, Washington.

International Monetary Fund (2009) World Economic Outlook, April 2009, Washington.

Leahy, J. (1993) “Investment in Competitive Equilibrium: The Optimality of Myopic Behaviour”, Quarterly Journal of Economics 108, 1105-1133.

Press, W.H., Teukolsky, S.A., Vetterling, W.T. and B.P. Flannery (1992) Numerical Recipes in C: The Art of Scientific Computing, 2nd edition, Cambridge (Cambridge University Press).

Ramey, Valerie A. and Matthew D. Shapiro (1998) "Displaced Capital", NBER Working Papers 6775, National Bureau of Economic Research, Inc.

Roberts, K. and M.L. Weitzman (1981) "Funding Criteria for Research, Development, and Exploration Projects”, Econometrica 49, 1261-1288.

Sichel, D.E. (1994) "Inventories and the Three Phases of the Business Cycle”, Journal of Business and Economic Statistics 12, 269-277.

Stokey, N.L. (2008) The Economics of Inaction: Stochastic Control Models with Fixed Costs, Princeton (Princeton University Press). 


\section{CESifo Working Paper Series}

for full list see www.cesifo-group.org/wp

(address: Poschingerstr. 5, 81679 Munich, Germany, office@cesifo.de)

2697 Steven Brakman, Charles van Marrewijk and Arjen van Witteloostuijn, Market Liberalization in the European Natural Gas Market - the Importance of Capacity Constraints and Efficiency Differences, July 2009

2698 Huifang Tian, John Whalley and Yuezhou Cai, Trade Sanctions, Financial Transfers and BRIC's Participation in Global Climate Change Negotiations, July 2009

2699 Axel Dreher and Justina A. V. Fischer, Government Decentralization as a Disincentive for Transnational Terror? An Empirical Analysis, July 2009

2700 Balázs Égert, Tomasz Koźluk and Douglas Sutherland, Infrastructure and Growth: Empirical Evidence, July 2009

2701 Felix Bierbrauer, Optimal Income Taxation and Public Goods Provision in a Large Economy with Aggregate Uncertainty, July 2009

2702 Marc Gronwald, Investigating the U.S. Oil-Macroeconomy Nexus using Rolling Impulse Responses, July 2009

2703 Ali Bayar and Bram Smeets, Government Deficits in the European Union: An Analysis of Entry and Exit Dynamics, July 2009

2704 Stergios Skaperdas, The Costs of Organized Violence: A Review of the Evidence, July 2009

2705 António Afonso and Christophe Rault, Spend-and-tax: A Panel Data Investigation for the EU, July 2009

2706 Bruno S. Frey, Punishment - and beyond, July 2009

2707 Michael Melvin and Mark P. Taylor, The Crisis in the Foreign Exchange Market, July 2009

2708 Firouz Gahvari, Friedman Rule in a Model with Endogenous Growth and Cash-inadvance Constraint, July 2009

2709 Jon H. Fiva and Gisle James Natvik, Do Re-election Probabilities Influence Public Investment?, July 2009

2710 Jarko Fidrmuc and Iikka Korhonen, The Impact of the Global Financial Crisis on Business Cycles in Asian Emerging Economies, July 2009

2711 J. Atsu Amegashie, Incomplete Property Rights and Overinvestment, July 2009 
2712 Frank R. Lichtenberg, Response to Baker and Fugh-Berman's Critique of my Paper, "Why has Longevity Increased more in some States than in others?", July 2009

2713 Hans Jarle Kind, Tore Nilssen and Lars Sørgard, Business Models for Media Firms: Does Competition Matter for how they Raise Revenue?, July 2009

2714 Beatrix Brügger, Rafael Lalive and Josef Zweimüller, Does Culture Affect Unemployment? Evidence from the Röstigraben, July 2009

2715 Oliver Falck, Michael Fritsch and Stephan Heblich, Bohemians, Human Capital, and Regional Economic Growth, July 2009

2716 Wladimir Raymond, Pierre Mohnen, Franz Palm and Sybrand Schim van der Loeff, Innovative Sales, R\&D and Total Innovation Expenditures: Panel Evidence on their Dynamics, July 2009

2717 Ben J. Heijdra and Jochen O. Mierau, Annuity Market Imperfection, Retirement and Economic Growth, July 2009

2718 Kai Carstensen, Oliver Hülsewig and Timo Wollmershäuser, Price Dispersion in the Euro Area: The Case of a Symmetric Oil Price Shock, July 2009

2719 Katri Kosonen and Gaëtan Nicodème, The Role of Fiscal Instruments in Environmental Policy, July 2009

2720 Guglielmo Maria Caporale, Luca Onorante and Paolo Paesani, Inflation and Inflation Uncertainty in the Euro Area, July 2009

2721 Thushyanthan Baskaran and Lars P. Feld, Fiscal Decentralization and Economic Growth in OECD Countries: Is there a Relationship?, July 2009

2722 Nadia Fiorino and Roberto Ricciuti, Interest Groups and Government Spending in Italy, 1876-1913, July 2009

2723 Andreas Wagener, Tax Competition, Relative Performance and Policy Imitation, July 2009

2724 Hans Fehr and Fabian Kindermann, Pension Funding and Individual Accounts in Economies with Life-cyclers and Myopes, July 2009

2725 Ernesto Reuben and Arno Riedl, Enforcement of Contribution Norms in Public Good Games with Heterogeneous Populations, July 2009

2726 Kurt Schmidheiny and Marius Brülhart, On the Equivalence of Location Choice Models: Conditional Logit, Nested Logit and Poisson, July 2009

2727 Bruno S. Frey, A Multiplicity of Approaches to Institutional Analysis. Applications to the Government and the Arts, July 2009 
2728 Giovanni Villani, A Strategic R\&D Investment with Flexible Development Time in Real Option Game Analysis, July 2009

2729 Luca Di Corato and Michele Moretto, Investing in Biogas: Timing, Technological Choice and the Value of Flexibility from Inputs Mix, July 2009

2730 Gilad D. Aharonovitz, Nathan Skuza and Faysal Fahs, Can Integrity Replace Institutions? Theory and Evidence, July 2009

2731 Michele Moretto and Sergio Vergalli, Managing Migration through Conflicting Policies: an Option-theory Perspective, July 2009

2732 Volker Nitsch, Fly or Cry: Is Airport Noise Costly?, July 2009

2733 Francesco Cinnirella and Joachim Winter, Size Matters! Body Height and Labor Market Discrimination: A Cross-European Analysis, July 2009

2734 Samuel Bowles and Sandra Polanía Reyes, Economic Incentives and Social Preferences: A Preference-based Lucas Critique of Public Policy, July 2009

2735 Gary Burtless, Lessons of the Financial Crisis for the Design of National Pension Systems, July 2009

2736 Helmuth Cremer, Firouz Gahvari and Pierre Pestieau, Fertility, Human Capital Accumulation, and the Pension System, July 2009

2737 Hans Jarle Kind and Frank Stähler, Market Shares in Two-Sided Media Industries, July 2009

2738 Pamela Campa, Alessandra Casarico and Paola Profeta, Gender Culture and Gender Gap in Employment, August 2009

2739 Sebastian Gechert, Supplementary Private Health Insurance in Selected Countries: Lessons for EU Governments?, August 2009

2740 Leif Danziger, Endogenous Monopsony and the Perverse Effect of the Minimum Wage in Small Firms, August 2009

2741 Yan Dong and John Whalley, A Third Benefit of Joint Non-OPEC Carbon Taxes: Transferring OPEC Monopoly Rent, August 2009

2742 Valentina Bosetti, Carlo Carraro and Massimo Tavoni, Climate Change Mitigation Strategies in Fast-Growing Countries: The Benefits of Early Action, August 2009

2743 Christina Felfe, The Willingness to Pay for Job Amenities: Evidence from Mothers' Return to Work, August 2009

2744 Jörg Franke, Christian Kanzow, Wolfgang Leininger and Alexandra Väth, Effort Maximization in Asymmetric N-Person Contest Games, August 2009 
2745 Bruno S. Frey and Paolo Pamini, Making World Heritage Truly Global: The Culture Certificate Scheme, August 2009

2746 Frank N. Caliendo, Is Social Security behind the Collapse of Personal Saving?, August 2009

2747 Caterina Liesegang and Marco Runkel, Corporate Income Taxation of Multinationals and Fiscal Equalization, August 2009

2748 Chrysovalantou Milliou and Apostolis Pavlou, Upstream Horizontal Mergers and Efficiency Gains, August 2009

2749 Rüdiger Pethig and Christian Wittlich, Interaction of Carbon Reduction and Green Energy Promotion in a Small Fossil-Fuel Importing Economy, August 2009

2750 Kai Carstensen, Oliver Hülsewig and Timo Wollmershäuser, Monetary Policy Transmission and House Prices: European Cross-country Evidence, August 2009

2751 Olaf Posch, Explaining Output Volatility: The Case of Taxation, August 2009

2752 Beatrice Scheubel, Daniel Schunk and Joachim Winter, Don't Raise the Retirement Age! An Experiment on Opposition to Pension Reforms and East-West Differences in Germany, August 2009

2753 Daniel G. Arce, Dan Kovenock and Brian Roberson, Suicide Terrorism and the Weakest Link, August 2009

2754 Mario Larch and Wolfgang Lechthaler, Comparative Advantage and Skill-Specific Unemployment, August 2009

2755 Horst Raff and Nicolas Schmitt, Buyer Power in International Markets, August 2009

2756 Seppo Kari, Hanna Karikallio and Jukka Pirttilä, The Impact of Dividend Taxation on Dividends and Investment: New Evidence Based on a Natural Experiment, August 2009

2757 Mirco Tonin and Michael Vlassopoulos, Disentangling the Sources of Pro-social Behavior in the Workplace: A Field Experiment, August 2009

2758 Nicole Grunewald and Inmaculada Martínez-Zarzoso, Driving Factors of Carbon Dioxide Emissions and the Impact from Kyoto Protocol, August 2009

2759 Yu-Fu Chen and Michael Funke, Booms, Recessions and Financial Turmoil: A Fresh Look at Investment Decisions under Cyclical Uncertainty, August 2009 